\title{
2-hexyl-4-pentynoic acid (HPTA), a novel radiosensitizer to breast cancer cells through increasing the instability of DNA repair proteins
}

\section{Zuchao Cai}

Shandong University

David Lim

Western Sydney University

Guochao Liu

Shandong University

Wenwen Ding

Shandong University

Zhendong Wang

Shandong University

Zhujun Tian

Shandong University

Junxuan Peng

Shandong University

Chao Dong

Shandong University

Fengmei Zhang

Shandong University

Zhihui Feng ( $\nabla$ fengzhihui@sdu.edu.cn )

Shandong University

\section{Research}

Keywords: 2-hexyl-4-pentynoic acid, radiosensitizer, breast cancer, DNA repair proteins, instability

Posted Date: September 24th, 2020

DOI: https://doi.org/10.21203/rs.3.rs-80703/v1

License: (c) (i) This work is licensed under a Creative Commons Attribution 4.0 International License.

Read Full License 


\section{Abstract \\ Background}

Breast cancer is one of the most common malignant tumors in the world which is the main cause of cancer death for women. Radiotherapy is the main treatment. Although some drugs have been found to enhance the effect of radiotherapy, there are also obvious deficiencies. Therefore, recent applied clinical research has been focusing on locating a suitable radiosensitizer to breast cancer radiotherapy.

\section{Methods}

MTT, clonogenic survival assays, comet assays, immunofluorescence and western blot analyses were used to detect the effect of VPA / HPTA on DNA damage induced by radiotherapy for breast cancer through a variety of cell models( MCF7, EUFA423, HCC1937, DMBA-induced rat breast cancer-derived primary culture cell and DMBA-induced transformed human normal breast cell line). At the same time, flow cytometry, immunofluorescence and western blot analyses were used to investigate the effect of VPA / HPTA on DNA damage repair induced by radiation. In vivo experiment, the effect of HPTA as radiosensitizer was investigated by DMBA-induced breast cancer in rats. Finally, the possible mechanism of HPTA acting on target protein was proved by cycloheximide chase experiment.

\section{Results}

In this study, a derivative of valproic acid (VPA), 2-hexyl-4-pentynoic acid (HPTA), was demonstrated for the first time that low concentration of HPTA $(15 \mu \mathrm{M})$ has radiosensitizing properties to breast cancer cells by multiple working models of breast cancer cell lines (in vivo), equivalent to a high concentration of VPA $(500 \mu \mathrm{M})$. Mechanistic investigations revealed that HPTA induced radiosensitivity through inhibiting the BRCA1-Rad51-mediated homologous recombination pathway. These results were further manifested in breast cancer animal model (in vitro). Most importantly, our study found that HPTA influenced the stability of BRCA1 and Rad51 proteins via shorting their half-life.

\section{Conclusions}

Our findings support the proposition HPTA as an alternate, safe and effective radiosensitizer to tumor cells. Targeting BRCA1-Rad51-mediated homologous recombination pathway through HPTA may be a rational strategy to improve the radiotherapeutic efficacy of breast cancer.

\section{Introduction}

Breast cancer is one of the most common malignant tumors in the world, with more than one million new cases every year and is the main cause of cancer death for women [1, 2]. Treatment for breast cancer - 
surgery, chemotherapy, and radiotherapy - have significantly improved the prognosis of patients and reduced the mortality of breast cancer [3]. Radiotherapy for breast cancer includes adjuvant radiotherapy after breast conserving surgery or after mastectomy, for local recurrence and distant metastasis (e.g. brain and bone). Radiotherapy has been shown to improved survival rate post-mastectomy, reduction in locoregional recurrent rate and ipsilateral breast cancer recurrences [4]. However, radiation to the breast has the potential to cause severe complications due to incidental dosage to heart, lungs and contralateral breast [5], incidence and severity of adverse events is dose and volume dependent [6]. All of these are considered the causes of treatment failure. Thus, acquiring a deeper understanding of the mechanisms related to radiotherapy and identifying a novel and suitable radiosensitizer are crucial events for improving the survival of breast cancer patients.

Valproic acid (VPA) is used in the treatment of epilepsy since the early 1970s [7-10]. In addition to its antiepileptic effect, VPA has been found to induce tumor cell death, inhibit tumor invasion and metastasis, and inhibit angiogeneis in various cancer models. More recent studies have also found VPA to increase the radiosensitivity of solid malignant tumor cells, including esophagus cancer [11], lung cancer [12], prostate cancer [13], and colon cancer [14]. Our previous studies have demonstrated that $500 \mu \mathrm{M}$ VPA increases the sensitivity of osteosarcoma U20S cells, breast cancer MCF7 cells and breast cancer tissue-derived primary cells to radiation therapy $[15,16]$. The mechanism involves inhibiting BRCA1-Rad51-mediated homologous recombination (HR) and Ku80-mediated non-homologous end joining (NHEJ) repairs, resulting in DSBs accumulation and tumor cell death. A high dose $(500 \mu \mathrm{M})$ is required for VPA's radiosensitization effects [16], this increases the likelihood of adverse side effects such as hepatotoxicity, nephrotoxicity, and teratogenicity [17-19]. It is therefore imperative to identify alternatives with low toxicity and high potency.

At present, whilst some VPA derivatives have been reported to show similar anti-tumor effects as highdose VPA, few have radiosensitizing effects. The 2-propyl-pentanoic acid 4-(3H-1,2-dithiole-3-thione-5-yl)phenyl ester (ACS2) [19], phospho-valproic acid (P-V; MDC-1112) [20], and 2-propyl- pentanoic acid 2methanesulfonylsulfanyl-ethyl ester (ACS33) [21] have shown some promise, high concentrations of these three derivates were needed to induce tumour cell death [22]. The derivative 2-hexyl-4-pentynoic acid (HPTA) has demonstrated a strong inhibition effect on HDACs activity in HeLa cells and cerebellar granule cells $[6,22]$. The $\mathrm{IC}_{50}$ of its inhibition on HDAC activity is $11-15 \mu \mathrm{M}$, lower than VPA (348$448 \mu \mathrm{M})$. Whilst HPTA has been reported to be possibly teratogenesis - caused brain malformation in pregnant mouse embryos - a significantly high dose is required $(1.25 \mathrm{mmol} / \mathrm{kg}$, equivalent to $227.85 \mathrm{mg} / \mathrm{kg}$ [23]; $450 \mu \mathrm{M})$. It remains unknown whether a lower dose of HPTA could be as effective as the high dose VPA as a radiosensitizer in breast cancer.

In this study, we discovered for the first time that $15 \mu \mathrm{M}$ HPTA has a similar radiosensitization effect on breast tumor cells as $500 \mu \mathrm{M}$ VPA. The mechanism involves disrupting the DNA repair pathway by reducing the half-life of both DNA repair proteins BRCA1 and Rad51. In conclusion, we reveal that HPTA may be an efficacious sensitizer for breast cancer radiotherapy, indicating that BRCA1 and Rad51 may be the promising targets for breast cancer radiotherapy. 


\section{Methods And Materials}

\section{Cell culture}

MCF7 and EUFA423 breast cancer cell lines and U20S cell lines were purchased from American Type Culture Collection (ATCC) and maintained in DMEM (12100046, Gibco) medium with 10\% Fetal Bovine Serum (10270106, Gibco) and 1\% Penicillin-Streptomycin (V900929, Sigma). MCF10A cell line was provided by Stem Cell Bank, Chinese Academy of Sciences, cultured with Dulbecco's Modified Eagle's Medium/Nutrient Mixture F-12 Ham(D9785, Sigma) combined with 5\% Horse Serum (26050088, Gibco), $100 \mathrm{ng} / \mathrm{ml}$ Cholera toxin (C8052, Sigma), $20 \mathrm{ng} / \mathrm{ml}$ Epidermal Growth Factor (E5036, Sigma), 0.5 $\mu \mathrm{g} / \mathrm{ml}$ Hydrocortisone(614157, Sigma), 10 $\mathrm{g} / \mathrm{ml}$ Human Insulin (19278, Sigma), and 1\% Penicillin-Streptomycin (V900929, Sigma). HCC1937 cells were stably transfected with the plasmids of pcDNA3-wild type BRCA1 (wtBRCA1) and vector control (pcDNA3), respectively. Parental HCC1937 cell line was cultured in RPMI 1640 Medium (c11875500bt, Gibco), combined with 10\% Fetal Bovine Serum (10270106, Gibco) and 1\% Penicillin-Streptomycin (V900929, Sigma). All cells were confirmed to be mycoplasma-free, and maintained at $37^{\circ} \mathrm{C}$ and $5 \% \mathrm{CO}_{2}$.

\section{Drug treatment and lonizing Radiation}

The cells were treated with VPA (BP452, Sigma) or HPTA (H0964, TCl) and were subjected to IR using Xray Irradiator (X-RAD225 OptiMAX, Pxi).

\section{MTT assay}

Cells were seeded in a 96-well plate at a density of $1 \times 10^{3}$ cells per well. Following treatments, MTT solution $\left(5 \mathrm{mg} / \mathrm{ml}\right.$, Sigma) was added to the treated cells and incubated for $4 \mathrm{~h}$ at $37^{\circ} \mathrm{C}$. Then the medium was replaced with dimethyl sulfoxide. The absorbance of the solution was measured using an enzyme immunoassay analyzer at $490 \mathrm{~nm}$.

\section{Clonogenic survival assay}

Cells were seeded in P60 dishes followed by the VPA, HPTA and IR treatment and cultured for about two weeks when the visible colonies formed. At the endpoint, cells were fixed with ethanol and stained with $0.1 \%$ crystal violet in $20 \%$ methanol for $30 \mathrm{~min}$. The detailed method was described in our previous publications $[15,16]$. The number of cell colonies was counted and cell survival was presented by the cell survival fraction (SF), with SF= (the number of clones/seeded cells)/plating efficiency (PE). These experiments were performed in triplicate.

\section{Comet assay}

The neutral comet assay and alkaline comet assay were performed for the detection of DSBs by using the Comet Assay kit (Trevigen, Gaithersburg, MD) following the manufacturer's instructions and was analyzed using CometScore software (TriTek, Sumerduck, VA).

\section{Immunofluorescence}


Cells were seeded in an eight-well chamber at a density of $3 \times 10^{4}$ cells per well. The methods were described in detail in our previous publications $[15,16]$. The primary antibodies used for immunoblotting analysis specific to $\mathrm{YH}_{2} \mathrm{AX}$ (1:500; 05-636, EMD Millipore), 53BP1(1:1000; NB100-304, Gene Tex), Rad51 (1:100; sc-8349, Santa Cruz), BRCA1 (1:100; sc-6954, Santa Cruz) were used. Secondary antibodies including Alexa Fluor 594 goat anti-mouse $\lg (\mathrm{H}+\mathrm{L})$ (1:300; A11032, Molecular probes), Alexa Fluor 488 chicken anti-rabbit $\lg G(H+L)(1: 300 ; A 21441$, Molecular probes). Images were captured using a fluorescence microscope (IX71 + DP73, Olympus).

\section{Immunoblotting}

The protocols were described in our previous publication [24]. The primary antibodies include: $\mathrm{\gamma H}_{2} \mathrm{AX}$ (1:500; 05-636, EMD Millipore), 53BP1(1:1000; NB100-304, Gene Tex), BRCA1 (1:200; sc-6954, Santa Cruz), BRCA1 (1:250; OP92, Calbiochem), Rad51 (1:200; sc-8349, Santa Cruz), Rad51 (1:2500; PC130, Calbiochem), Ku70 (1:200; sc-5309, Santa Cruz), Ku80 (1:200; sc-5280, Santa Cruz), DNA-PKcs (1:5000; ab32566, abcam), $\beta$-actin (1:2000, TA-09, ZSGB-BIO)and GAPDH (1:2000, TA-08, ZSGB-BIO). The secondary antibodies were goat anti-mouse $\lg G(H+L)(1: 5000,31430$, Thermo Fisher) and goat antirabbit lgG $(H+L)(1: 5000,31460$, Thermo Fisher).

\section{DSB assay}

For HR assay, the MCF7 cell line expressing a recombination substrate of the pDR-GFP reporter was studied to determine the number of GFP-positive cells in the treated cells for the analysis of the spontaneous HR frequency using flow cytometry as described previously $[15,16]$. For NHEJ assay, the U2OS cell line expressing an End Joining reporter (EJ5-GFP) was studied to determine the number of GFP-positive cells in the treated cells for the analysis of the spontaneous NHEJ frequency using flow cytometry as described previously [25].

\section{Animal keeping and the establishment of breast cancer model}

Female Sprague-Dawley (SD) rats were purchased from Pengyue Laboratory Animal Co. Ltd. Jinan, China. The studies of animal tissue were performed in adherence to national standards on animal care, specificially the Shandong University Human and Animal Ethics Research Committee's requirements (project identification code 81472800, approved on 3 March 2014). All rats were housed in a specificpathogen-free environment, at a temperature of $23 \pm 1^{\circ} \mathrm{C}$. The lights were at a daily rhythm of $12 \mathrm{hrs}$ and the rats were fed fresh food and water ad libitum throughout the experiment. The DMBA (Sigma) was dissolved in purified corn oil and adjusted to the concentration of $20 \mathrm{mg} / \mathrm{ml}$. Intragastric gavage (i.g.) was performed on 50-day-old SD rats at a single dose of $1 \mathrm{ml} \mathrm{DMBA-oil} \mathrm{solution} \mathrm{[26,} \mathrm{27].} \mathrm{At} \mathrm{40-60} \mathrm{days}$ after gavage, primary tumors could be detected through palpation around the breast.

\section{Tumor observation on rats}

For a period of time after DMBA gavage, rats with appropriate tumor size and location were selected for grouping and then treated. The tumor size of each group was recorded and measured with a vernier 
caliper. Tumor volume was calculated according to the clinical standard formula "Volume $\mathrm{V}\left(\mathrm{mm}^{3}\right)=$ Length $(\mathrm{L})$ * Width $(\mathrm{W})^{2}$ * $0.5 "$.

\section{$\mathrm{HE}$ and immunohistochemistry (IHC) staining}

The rats were given chloral hydrate (Sigma) for the anesthesia and breast tissues and cancer tissues were isolated, then fixed overnight in $4 \%$ paraformaldehyde solution, embedded in paraffin and serially sectioned $5 \mu \mathrm{m}$ thick for $\mathrm{HE}$ and $\mathrm{IHC}$ staining.

The sections for IHC staining were dewaxed with xylene and hydrated with $100-75 \%$ ethanol. And then boiled in a $10 \mathrm{mM}$ sodium citrate solution above $92^{\circ} \mathrm{C}$ for 20 minutes for antigen retrieval. The sections were cooled to room temperature and then washed with TBS. After washing with TBS, incubate the sections in $3 \%$ hydrogen peroxide for 15 minutes to remove endogenous peroxidase and washed again with TBS. Incubate with $10 \%$ goat serum for 1 hour to block non-specific binding, then dilute $\mathrm{YH}_{2} \mathrm{AX}$ (1:500,05-636, EMD Millipore) and Rad51 (1:500; PC130, Calbiochem)with solution (TBS + 1\% BSA) primary antibody, and the sections were placed at $4{ }^{\circ} \mathrm{C}$ overnight. Secondary antibody was diluted by TBST (TBS + 0.25\% Triton X-100 + 1\% BSA): Biotinylated goat anti-mouse IgG (1:300, BA-9200, Vector), Biotinylated goat anti-rat IgG (1:300, BA-9400, Vector) and incubated sections for 1 hour at room temperature. Wash with TBST and immediately incubated in $A B C$ working solution for 30 minutes, then test with DAB working solution. Subsequently, hematoxylin staining was carried out, and it was dehydrated with ethanol after washing, and then fixed with xylene for 5 minutes, observed with neutral gum.

The IOD density of $\mathrm{yH}_{2} \mathrm{AX}$ and Rad51 staining by IHC staining was further quantified by Image pro plus software (Media Cybernetics).

\section{Chemical carcinogen-induced rat breast cancer-derived primary cells}

The method was described in our previous publication [28]. After establishment of the breast cancer model, the rats were given chloral hydrate (Sigma) for the anesthesia and breast cancer tissues were isolated in a sterile manner. The breast cancer tissues were further cut into small pieces $(2 \times 2 \mathrm{~mm})$ and placed on the coated dishes for primary cell culture. The cells from the second and third passage were used for the immunofluorescence analysis of $\mathrm{YH} 2 \mathrm{AX}$ and 53BP1.

\section{Soft agar colony formation assay}

For the bottom layer, $1.5 \mathrm{ml} /$ well $0.6 \%$ low-melting agar (214230, Difco Agar Nobel) was added into a 6well plate for solidification. The top layer contained cell suspension $(1 \times 104 /$ well $)$ and $0.3 \%$ agar. The cells were cultured for $3-4$ weeks until visible colony formed, these were stained with $0.005 \%$ crystal violet.

\section{Rl-1 assay}


Cells were seeded onto $60 \mathrm{~mm}$ dishes with cell culture media supplemented with $10 \mu \mathrm{M}$ Rad51 inhibitor 1 (RI-1, S8077, Slleck ) pretreated for 24hrs. Cells were harvested at indicated time points, and lysates were subjected to Western blotting experiments to analyze protein expression at indicated time points. Image $\mathrm{J}$ software was used to quantify the relative expression level compared with control treatment.

\section{Cycloheximide Chase Experiment}

Cells were seeded onto $60 \mathrm{~mm}$ dishes with cell culture media supplemented with $40 \mu \mathrm{g} / \mathrm{mL}$ cycloheximide (CHX, HY-12320, MedChemExpress ). Cells were harvested at indicated time points, and lysates were subjected to Western blotting experiments to analyze protein expression at indicated time points. Image $\mathrm{J}$ software was used to quantify the relative expression level compared with control treatment.

\section{Statistical analysis}

All statistical analyses were performed with Student's t-test on SPSS Statistics for Windows, Version 23.0 (Armonk, NY: IBM Corp; licensed to Shandong University). and represented as mean \pm SD. The $p$ values were designated as: ${ }^{*}, P<0.05 ;{ }^{* *}, P<0.01$, indicating a statistically significant difference.

\section{Results}

\section{HPTA results in the accumulation of more DSBs in response to radiation}

Our previous research showed that $500 \mu \mathrm{M}$ VPA inhibits the proliferation of multiple breast cancer cells and increases the sensitivity of cells to radiation [16]. To explore whether HPTA has a similar effect on breast cancer cells with VPA, we performed MTT experiments using HPTA in MCF7 cells. Accordingly, we set three concentrations: $15 \mu \mathrm{M}, 30 \mu \mathrm{M}$, and $60 \mu \mathrm{M}$ HPTA against $500 \mu \mathrm{M}$ VPA (positive control) and subject to $4 \mathrm{~Gy}$ of ionizing radiation (IR). We found that cell proliferation in the VPA-/HPTA-treatment groups was inhibited after IR treatment as anticipated $(P<0.01)$ (Figure. 1B). There were no statistical differences between the three different concentrations of HPTA as compared to $500 \mu \mathrm{M}$ VPA, indicating that HPTA at a low concentration $(15 \mu \mathrm{M})$ possesses similar radiosensitizing effect as $500 \mu \mathrm{M}$ VPA. Based on the $\mathrm{IC}_{50}$ of VPA and HPTA, we opted for $15 \mu \mathrm{M}$ HPTA for further experiments.

We next performed a clonogenic assay on the MCF7 cells (Figure. 1C). To better compare the effects of HPTA and VPA, we added $15 \mu \mathrm{M}$ VPA as a negative control. At the same time, to observe cell survival at different IR doses, we also included t 2, 4, and $6 \mathrm{~Gy}$. The results showed that there was no statistical difference between VPA $(15 \mu \mathrm{M}$ or $500 \mu \mathrm{M})$ and HPTA treatment $(15 \mu \mathrm{M})$ in the unirradiated control group (Figure. 1D upper, $P>0.05$ ). HPTA- treated cells were more sensitive to IR as compared to the untreated control group (Figures. 1C \& 1D, $P<0.05$ ). But VPA was more sensitive only at $500 \mu \mathrm{M}$, and there was no difference between the untreated control group and the VPA at a low concentration of $15 \mu \mathrm{M}$, which also proved that HPTA was more effective. Similar results were observed in another breast cancer cell line, 
EUFA423 (Figure. S1A\&1B). These data indicate that the $15 \mu \mathrm{M}$ HPTA has similar radiosensitizing effects as $500 \mu \mathrm{M}$ VPA in vitro.

Our previous research [16] has shown that $500 \mu \mathrm{M}$ VPA could cause significant DSBs following IR treatment, to explore whether the low concentration of HPTA would result in similar DSBs after IR treatment, DSBs were evaluated by two experiments using comet and immunofluorescence assays. To maximize the DSBs in cells, we set the IR dose at 8 Gy. In MCF7 cells, the alkaline comet assay showed no significant change in the VPA- or HPTA- treatment alone compared with the untreated control group pre-IR $(P>0.05$; Figure. 1E). At 0 min post-IR treatment, the relative DSBs in the $500 \mu \mathrm{M}$ VPA (70.04) and $15 \mu \mathrm{M}$ HPTA treatment group (69.06) were significantly higher than that of the control group $(52.43)(P<$ 0.01 ; Fig. 1E), indicating that VPA or HPTA in combination with IR can further increase intracellular DSBs accumulation. At 30 min post-IR treatment, the comet tail length began to shorten, but in the VPA treatment group (48.52) and the HPTA treatment group (49.70), the comet tail length was still significantly longer than that of the IR treatment alone (36.79) $(P<0.01$; Figure. 1E). At 120 min post-IR treatment, the tail length became shorter and gradually recovered, while the tail length of the VPA treatment group (31.53) and the HPTA treatment group (31.32) was also significantly longer than that of the control alone (20.58) $(P<0.01)$. Similar results were obtained from the neutral comet experiments (Figure. 1F). The above observations were further validated in the EUFA423 cells (Figure. S1C\&1D).

DNA DSBs biomarkers $\mathrm{\gamma H} 2 \mathrm{AX}$ and 53BP1 were employed to determine whether $15 \mu \mathrm{M}$ HPTA can enhance IR-induced DSBs. Immunofluorescence assay showed that the proportion of MCF7 cells with $\mathrm{YH} 2 \mathrm{AX}$ or 53BP1 foci formation in the VPA-/HPTA-treatment alone was not increased compared with the control group ( $P>0.05$; Figure. $1 \mathrm{G})$. The proportion of MCF7 cells with YH2AX or 53BP1 foci increased significantly 6 hrs post-IR $(81.37 \%$ and $87.34 \%$ respectively; Figure. $1 \mathrm{H})$. The percentage of $\mathrm{YH} 2 \mathrm{AX}$ or 53BP1 foci in the VPA-/HPTA- treatment group was further increased as compared to the control: 98.59\%/97.50\% ( $\mathrm{YH} 2 \mathrm{AX})$ and $98.28 \% / 98.21 \%(53 \mathrm{BP} 1)(P<0.01$; Figure. $1 \mathrm{H})$, indicating that $15 \mu \mathrm{M}$ HPTA can generate a similar amount of DNA DSBs as $500 \mu \mathrm{M}$ VPA. Next, we observed the clearance of $\gamma \mathrm{H} 2 \mathrm{AX}$ and 53BP1 foci. At $24 \mathrm{hr}$ post-IR treatment, the $\mathrm{YH} 2 \mathrm{AX}$ and 53BP1 foci disappeared significantly slower in the VPA-/HPTA- treatment group as compared to the control group $(P<0.01$; Figure. $1 \mathrm{H})$, indicating that $15 \mu \mathrm{M}$ HPTA is equivalent to $500 \mu \mathrm{M}$ VPA in affecting the ability of cells to repair DNA damage. We analyzed the above data by categorizing the cells containing YH2AX or 53BP1 foci into two groups based on the number of foci in each cell: small foci $(n<20)$ and big foci $(n \geq 20)$. The results in Figure. S2A showed that the proportion of cells containing big foci in the VPA-/HPTA- treatment group was significantly higher than that in the control group. We next detect the protein levels of YH2AX and 53BP1 by an immunoblotting assay (Figure. 1I). The levels of $\mathrm{YH} 2 \mathrm{AX}$ and 53BP1 were increased by IR treatment, and further increased in the VPA-/HPTA treatment group $(P<0.01$; Figure. $1 \mathrm{~L})$. The results from the above experiments indicate that $15 \mu \mathrm{M}$ HPTA enhances IR-induced DSBs, similar to $500 \mu \mathrm{M}$ VPA. We further verified the above results in the EUFA423 cells (Figure. S1E-1H).

In summary, in both MCF7 and EUFA423 cells, our data demonstrate that $15 \mu \mathrm{M}$ HPTA can lead to a similar extent of DSBs as $500 \mu \mathrm{M}$ VPA in breast cancer cells after IR treatment. 


\section{Low dose HPTA dysregulates DNA repair pathway in response to IR-induced DSBs}

We next tested the DSB repair process in breast cancer cells to determine the likely mechanism of HPTA's action.

Mammalian cells employ two major DNA repair pathways: homologous recombination (HR) and nonhomologous end-joining (NHEJ), to maintain cell survival [29-31]. Error-free HR repair requires a homologous template such as a sister chromatid, whereas NHEJ joins the two ends of a DSB through a process largely independent of homology [32]. Our previous research also showed that $500 \mu \mathrm{M}$ VPA reduces HR efficiency [16], so we next explore whether $15 \mu \mathrm{M}$ HPTA has the same effect on the frequency of HR in the above cell models. The MCF7 cells expressing the pDR-GFP recombination reporter for the HR frequency assay were subjected to flow-cytometry after the introduction of I-Scel-induced DSBS (Figure. 2A). The HR frequency decreased in cells treated with $15 \mu \mathrm{M}$ HPTA by $42.88 \%$ as compared to the cells without HPTA treatment $(P<0.01$; Figure. 2B), indicating that low concentration of HPTA is sufficient to dysregulate HR repair pathway.

Recombinase Rad51 plays a central role in the HR mechanism and our previous studies have also shown that the effect of VPA on the HR pathway is mediated by Rad51 [16]. Thus, we investigated whether HPTA influences the Rad51-mediated HR pathway. The results from the immunofluorescence assay showed that the percentage of the cells with Rad51 foci formation in the VPA-/HPTA- treatment group was almost the same as the control group pre-IR treatment $(P>0.05$; Figure. $2 \mathrm{C})$. At $6 \mathrm{hr}$ post-IR treatment, the percentage of cells with Rad51 foci in the IR control group was $77.91 \%$, and were reduced by $13.31 \%(P<$ $0.01)$ and $14.04 \%(P<0.01)$ in the VPA-/HPTA- treatment groups (Figure. $2 \mathrm{C} \& 2 \mathrm{D}$-upper). At $24 \mathrm{hr}$ post-IR treatment, the Rad51 foci decreased as DNA repairs gradually completed, the VPA-/HPTA- treatment group still showed a significant decrease in Rad51 foci formation, a reduction by $10.39 \%(P<0.01)$ and 9.65\% $(P<0.01)$ respectively as compared with the control group (46.51\%) (Figure. 2C \& 2D-upper). The results were verified by immunoblotting. At 6 hrs post-IR treatment, Rad51 protein level reduced significantly in both the VPA and HPTA treatment groups as compared to the IR treatment alone $(P<0.01$; Figure. 2E \& 2F). This indicated that $15 \mu \mathrm{M}$ HPTA impaired Rad51 activity after IR, and the HPTA inhibited HR pathway is Rad51-dependent.

BRCA1 is another important protein that regulates HR via its interaction with Rad51 [33], so we next determined whether BRCA1 activity was influenced by HPTA. Through immunofluorescence and immunoblotting experiments, we observed similar results as per Rad51(Figure. $2 \mathrm{C}-2 \mathrm{~F}$ ). The results were verified in EUFA423 cells (Figure. S3A - 3D).

To next investigate the possibility that HPTA may also influence the NHEJ repair in our cell models, we used U2OS cells expressing the EJ5-GFP reporter to measure the NHEJ frequency [25,34] using flowcytometry after the generation of I-Scel-induced DSBs (Figure. S4A). The NHEJ frequency decreased in 
cells treated with $15 \mu \mathrm{M}$ HPTA by $19.48 \%$ as compared to the cells without HPTA treatment $(P<0.05$; Figure. S4B), indicating that HPTA leads to the disruption of the NHEJ pathway.

A number of proteins are involved in the NHEJ repair pathway, such as DNA-PKcs, Ku70 and Ku80 [16]. Since our data demonstrated that HPTA had a suppressive effect on NHEJ, it would be reasonable to detect whether HPTA influences the major NHEJ-associated proteins. We next employed immunoblotting assay to detect DNA-PKcs, Ku70 and Ku80 proteins in our cell models. The immunoblotting assay results in MCF7 cells showed that after 8 Gy IR, no significant changes in the three proteins were observed $(P>$ 0.05; Figure.S4C \& S4D). Similar results were also noted in the EUFA423 cell line (Figure. S4E). However, the expression of Ku70 and Ku80 proteins was decreased in the VPA treatment group as compared with the IR-control group $(P<0.05)$, but not in the HPTA treatment group (Figure. S4F). These results indicate that HPTA and VPA are different in the role of key proteins in NHEJ pathway. Through flow-cytometry, we found that HPTA could reduce the NHEJ efficiency (19.48\%), even if it was not as obvious as the reduction in HR efficiency (42.88\%), but the changes of several key proteins in different cells were not consistent, so we next focused on the effect of HPTA on HR.

\section{HPTA exhibits radiosensitizing properties to IR treatment in DMBA-induced breast cancer in rats in vivo}

To study whether HPTA has a radiosensitization effect in vivo, we first investigated the appropriate dose of HPTA on rat breast tumor. The primary model of transformed breast tumor cells in rats was induced by the environmental carcinogen 7,12-dimethylbenz[a]anthracene (DMBA). This was previously described and employed in related studies [28]. The experimental scheme is shown in Fig. 3A. In brief, around 40 days after DMBA gavage to female Sprague Dawley rats, lumps in breast sites could be found. The shape of lumps in the location of mammary glands was irregular (Figure. 3B). By HE staining (Figure. 3C), compared with normal breast tissue, abnormal hyperplasia, fibroadenoma and abnormal proliferation of epithelial cells of the breast were found, indicating that breast cancer in rats was successfully induced.

Reported studies of VPA on glioblastoma utilized intraperitoneal injection of VPA in the range from $150 \mathrm{mg} / \mathrm{kg}$ to $600 \mathrm{mg} / \mathrm{kg}$ [35]. Therefore, we choose $200 \mathrm{mg} / \mathrm{kg}$ as the treatment dose of VPA, which was equivalent to its dose of $500 \mu \mathrm{M}$ used in vitro experiments.

However, the concentration of HPTA in rats has not been reported. In our pilot experiment, four concentrations: $5 \mathrm{mg} / \mathrm{kg}, 10 \mathrm{mg} / \mathrm{kg}, 20 \mathrm{mg} / \mathrm{kg}$ and $50 \mathrm{mg} / \mathrm{kg}$ were used. After intraperitoneal injection, there was no change in the $5 \mathrm{mg} / \mathrm{kg}$ dose group, while the $10 \mathrm{mg} / \mathrm{kg}, 20 \mathrm{mg} / \mathrm{kg}$ and $50 \mathrm{mg} / \mathrm{kg}$ concentration showed the same performance as that after the $200 \mathrm{mg} / \mathrm{kg}$ VPA injection, but only $20 \mathrm{mg} / \mathrm{kg}$ dose group was close to $200 \mathrm{mg} / \mathrm{kg}$ VPA, and the rest lasted for a shorter or longer time. Therefore, we opted for $20 \mathrm{mg} / \mathrm{kg} \mathrm{HPTA}$ as the treatment dose for the study, this is equivalent to $15 \mu \mathrm{M}$ used in the in vitro experiments.

To achieve better therapeutic effect, we next experimented with four fractionated doses of 2 Gy IR which more closely mirrored the clinical IR treatment used in breast cancer [36]. VPA or HPTA were administrated before, during, and after IR treatment (Figure. 3D). All the rats were alive over the 32 days 
observation period. As shown in Fig. 3E, at the second day post-IR treatment, IR induced a $21 \%$ decreased in breast cancer volume, and the addition of VPA or HPTA further reduced the cancer volume by $62 \%$ and $54 \%$. During the 32 days of observation, compared with the IR treatment alone, the VPA-/ HTPA- treatment group significantly reduced the tumor volume $(P<0.05)$. The tumors in the IR treatment control group had recovered to the volume before IR, while the VPA-/ HPTA- treatment group had recovered to about half of the tumor volume before IR. On the 10th day after treatment, we excised the tumors under general anesthesia (Figure. 3E- right), the tumor size in the VPA-/ HTPA- treatment groups were smaller than that in the IR treatment control group.

The morphological structure of tumors was observed by HE staining (Figure. 3F). VPA or HPTA treatment led to vacuole structures formation in the breast cancer tissue as compared with the untreated group; there were more vacuoles structures and number of necrotic cells after the IR treatment, and large necrotic areas and cells were seen in the tissues in both VPA and HPTA treatment groups. The morphological findings are consistent with the above findings. The results demonstrated that $20 \mathrm{mg} / \mathrm{kg}$ HPTA or $200 \mathrm{mg} / \mathrm{kg}$ VPA can effectively sensitize breast cancer to IR treatment.

Next, we explored whether DNA damage and repair proteins were influenced by HTPA in vivo using the DSBs marker $\mathrm{YH} 2 \mathrm{AX}$. Whole-cell lysate extracted from the tumor tissue was analyzed for $\mathrm{YH} 2 \mathrm{AX}$ using Western blot. The results showed that there were DSBs in both VPA and HPTA treatment groups (Figure. $3 \mathrm{G})$, and the concentration of $\mathrm{YH} 2 \mathrm{AX}$ in both groups was higher than that in the untreated control group. The concentration of $\mathrm{YH} 2 \mathrm{AX}$ post-IR treatment was significantly increased, significantly higher in VPA treatment group $(P<0.05)$ and no difference between the HPTA treatment group and the IR control group. We speculated that the reason why there was no obvious change in the tumor tissue of HPTA combination group might be related to the cell lysate containing the protein components of non-tumor cells (connective tissue cells, such as fibroblast, macrophages, etc.), so we further studied the expression of $\mathrm{YH} 2 \mathrm{AX}$ by immunohistochemistry to verify this possibility. We found that compared with other groups, the amount of $\mathrm{YH} 2 \mathrm{AX}$ in the tumor areas of the VPA and HPTA treatment groups increased significantly $(P<0.01$; Figure. $3 \mathrm{H})$. The result showed that more DSBs in tumor cells was induced by the combination of HPTA and IR. The level of Rad51 in the VPA-/ HPTA- treatment group was significantly lower than that in IR control group $(P<0.01$; Figure. 31$)$. We also stained Rad51 with immunohistochemistry, and the results were consistent with those of Western blot (Figure. $4 \mathrm{~J}$ ).

Based on the in vivo and in vitro experiments, we concluded that HPTA, like VPA, can induce DSBs in tumor cells under IR and inhibit Rad51 function in DNA recombination process.

\section{The role of HPTA on the radiosensitivity of DMBA-induced rat breast cancer-derived primary culture cells}

Based on the model of breast cancer in rats, we designed the experiment of breast cancer-derived primary culture cells according to Fig. 4A. Immunofluorescence assay showed that there were no significant changes in cells with $\mathrm{YH} 2 \mathrm{AX}$ or 53BP1 foci formation in the VPA-/HPTA- treatment group compared with the untreated control group (Figure. 4B \& 4C). At 6 hr post-IR treatment, the positive rate of cells with 
$\mathrm{YH} 2 \mathrm{AX}$ or 53BP1 foci formation in the IR control group (90.04\%) increased significantly from baseline (Figure. 4C). Importantly, the rate in the VPA-/HPTA- treatment group was further increased to $100 \%(P<$ 0.05 ; Figure. $4 \mathrm{C}$ ), indicating that $15 \mu \mathrm{M}$ HPTA induces DSBs in cells similar to $500 \mu \mathrm{M}$ VPA. Next, we observed the clearance of $\mathrm{YH} 2 \mathrm{AX}$ and 53BP1 foci. At $24 \mathrm{hr}$ post-IR treatment, the $\mathrm{YH} 2 \mathrm{AX}$ and 53BP1 foci in the IR treatment alone were significantly decreased than in the VPA-/HPTA- treatment group $(P<0.01$; Figure. 4 C), suggesting that HPTA significantly affect DNA repair activity in cells and delay DNA repair process. Consistent results were obtained from our further analysis (Figure. S2C). Together, the results supported our hypothesis that IR-HPTA combination promotes more DSBs accumulation in primary tumor cells.

\section{The role of HPTA on the radiosensitivity of DMBA-induced transformed human normal breast cell line}

To triangulate the findings that low concentration of HPTA $(15 \mu \mathrm{M})$ can promote radiosensitivity, we next test the findings using the DMBA-induced transformed human normal breast cell line, MCF10A. Similar to the rat model mentioned above, the MCF10A cells were treated with $20 \mu \mathrm{g} / \mathrm{ml}$ DMBA for $24 \mathrm{hr}$ then cultured for around 60 days (Figure. 5A-up). The colonies of transformed cells were significantly formed compared to the control group using soft agar-colony formation assay (Figure. 5A-down).

The cell survival of the DMBA-induced transformed cells was tested by clonogenic assay (Figure. 5B). The results showed that there was no statistical difference in cell planting efficiency between groups (Figure. 5B). The survival fraction in the VPA-/ HPTA- treatment group was significantly decreased as compared to the IR treatment alone in transformed cells after $4 \mathrm{~Gy}(P<0.05)$ and $6 \mathrm{~Gy}(P<0.01) \mathrm{IR}$ treatment (Figure. 5B-right). The survival fraction of untransformed MCF10A human breast cancer cells in the VPA-/HPTA-treatment group did not alter after IR (Figure. S5A\&5B).

Next, we verified HPTA's radiosensitizing effect on DMBA-induced transformed MCF10A cells. DSBs in the tumor cells were observed by immunofluorescence assay using $\mathrm{YH} 2 \mathrm{AX}$ and $53 \mathrm{BP} 1$ biomarkers. The percentage of cells containing $\mathrm{YH} 2 \mathrm{AX}$ or 53BP1 foci significantly increased $6 \mathrm{hr}$ after IR treatment $(P<$ 0.01 ; Figure. 5C \& 5D), the proportion was further increased by VPA-/ HPTA- treatment $(P<0.01)$. At $24 \mathrm{hr}$ post IR treatment, the $\mathrm{YH} 2 \mathrm{AX}$ and 53BP1 foci resolved significantly slower in the VPA-/HPTA- treatment group than in the IR control group ( $P<0.01$; Figure. 5C \& 5D), indicating that $15 \mu \mathrm{M}$ HPTA affects the ability of transformed cells to repair damaged DNA.

We detected the protein levels of $\mathrm{YH} 2 \mathrm{AX}$ and 53BP1 protein by immunoblotting assay. Similarly, the expression of the two proteins in the VPA-/HPTA- treatment group was significantly higher than that of the IR control group $(P<0.05$; Figure. 5E \& 5F), which was consistent with the immunofluorescence results. In the untransformed MCF10A cells, no statistically significant differences between treatment groups were observed (Figure. S5C - S5F).

To investigate whether HPTA-regulated radiosensitizing effect is associated with DNA repair function in the DMBA-transformed MCF10A cells, the activity of HR associated proteins Rad51 and BRCA1 were 
examined. The immunofluorescence assay showed that the number of cells containing Rad51 or BRCA1 foci was significantly decreased in the VPA-/HPTA- treatment group as compared to the IR control group at $6 \mathrm{hr}$ and $24 \mathrm{hr}$ post-IR $(P<0.01$; Figure. 5G \& 5H). We next detect the protein levels of the Rad51 and BRAC1 in the transformed cells. The protein levels of Rad51 and BRCA1 had decreased in the VPA-/HPTAtreatment group ( $P<0.01$; Figure. $5 \mathrm{I} \& 5 \mathrm{~J})$ as compared to IR control group; though not in untransformed MCF10A cells (Figure. S5G - S5J). These data further indicate that HR function was significantly inhibited in the VPA-/HPTA- treatment group in DMBA-transformed MCF10A cells, consistent with our earlier studies reported above.

\section{HPTA-mediated radiosensitization to breast cancer cells is dependent on BRCA1 and Rad51 proteins}

We used multiple breast cancer cell lines (MCF7 and EUFA423, primary cultured rat breast cancer cell lines, and DMBA-induced transformed human normal breast cell line) and breast cancer animal model, to investigate whether the radiosensitizability of lower concentration of HPTA $(15 \mu \mathrm{M})$ is associated with BRCA1-Rad51-mediated HR activity.

The HCC1937 cell line expressing a defective BRCA1 gene was used to establish an isogenic wild type BRCA1 reconstituted cell line (wtBRCA1) (Figure. 6A). The clonogenic assay was employed to analyze the surviving fraction in HCC1937 cells expressing wtBRCA1 in response to IR. The VPA-/ HPTA- treatment group did not significantly decrease survival fraction (plating efficiency) in the paired cells as compared with untreated cells pre-IR (Figure. 6B \& 6C-up). The survival curve showed that HCC1937 cell expressing defective BRCA1 was more sensitive to IR as compared with BRCA1 cells (Figure. 6B \& 6C-down). Furthermore, the survival fraction in VPA-/HPTA-pretreated BRCA1 cells was significantly reduced after 4 Gy and 6 Gy IR, similar to BRCA1 defective cells in response to DNA damage (Figure. 6C-down). The survival fraction in VPA-/HPTA-pretreated BRCA1-deficient cells only moderately decreased compared to wtBRCA1-cells after IR. These results indicated that HPTA treatment led to cell death by inhibiting BRCA1mediated HR repair pathway in response to IR.

To investigate whether Rad51 is directly involved in the observed HPTA's radiosensitizing effect, we used RI-1 [37], an inhibitor of Rad51, in the MCF7 cells. After treatment with $10 \mu \mathrm{M} \mathrm{RI-1} \mathrm{for} 24$ hrs, the expression of Rad51 protein was significantly inhibited (Figure. 6D). The clonogenic assay was employed to analyze the surviving fraction in MCF7 cells in response to IR. We noted that HPTA treatment alone did not decrease survival fraction (plating efficiency) as compared with untreated cells, irrespective of RI-1 treatment pre-IR (Figure. 6E \& 6F-up). The survival curve showed that MCF7 untreated with RI-1 was more sensitive to IR treatment as compared with cells treated with Rl-1 (Figure. 6E\&6F-down). Furthermore, the survival fraction in VPA-/HPTA-pretreated MCF7 cells was significantly reduced after IR, similar to cells treated with RI-1 upon DNA damage, especially under 4 and 6 Gy treatment (Figure. 6F-down). However, in RI-1-treated cells, the survival fraction in VPA-/HPTA-pretreated cells did not decrease compared to MCF7 untreated with RI-1 after IR. The results indicated that HPTA treatment, like and VPA, can lead to cell death via inhibiting Rad51-mediated HR repair pathway in response to IR. 
In the established BRCA1 and Rad51 isogenic cell lines, we demonstrated that HPTA- and VPA-induced radiosensitization in breast cancer cells is associated with BRCA1-Rad51 mediated pathway.

\section{HPTA increases the sensitivity of breast tumor cells to radiotherapy by inhibiting BRCA1 and Rad51 protein synthesis and shortening their half-life}

We next investigate how does HPTA affects sensitize tumor cells to IR. Cycloheximide (CHX) which hinders the translation process by interfering with shifting steps in protein synthesis, is often used to inhibit protein synthesis in eukaryotic cells [38-41]. We designed $\mathrm{CHX}$-chase experiment to measure the half-life of the Rad51 and BRCA1 proteins in MCF7 cells. Immunoblotting was employed to analyze the expression of BRCA1 and Rad51 protein in the treated cells. Prior to IR, the HPTA treatment group and the negative control group showed an inverse association with the duration of $\mathrm{CHX}$ treatment and there was no significant difference between them $(P>0.05$; Figure. 7A \& 7B). After IR treatment, the protein level of BRCA1 in the control group decreased to $54.45 \%$ and $36.61 \%$ at 4 and 8 hrs post-CHX treatment respectively, while in the HPTA treatment group was decreased to $55.29 \%$ and $31.39 \%$ only at 2 and 4 hrs post- $\mathrm{CHX}$ treatment respectively (Figure. 7B). The findings suggest that the half-life of BRCA1 protein in the HPTA treatment group was shortened by $2 \mathrm{hrs}$ and that HPTA can inhibit the synthesis of BRCA1 protein. The change of Rad51 protein after $\mathrm{CHX}$ treatment was similar to that of BRCA1 (Figure. 7A \& 7C). Collectively, HPTA inhibits the synthesis of both BRCA1 and Rad51, shortens their half-life and sensitizes tumor cells to IR.

\section{Conclusion}

In summary, we discovered for the first time in this study that $15 \mu \mathrm{M}$ HPTA has a similar radiosensitization effect on breast tumor cells as $500 \mu \mathrm{M}$ VPA. The mechanism involves disrupting the HR repair pathway by inhititing both DNA repair proteins BRCA1 and Rad51, as proposed in Fig. 8. Given that HPTA can reduce the half-life of BRCA1 and Rad51 proteins, targeting BRCA1 and Rad51 may be a desirable therapeutic strategy for HPTA to enhance breast cancer radiotherapy.

\section{Discussion}

The overexpression of HDACs was extensively investigated in many cancers [42, 43]. HDACis inhibit histone acetylation and result in transcriptionally inactive chromatin [26, 44, 45]. Increasing evidence show that many HDACis not only have potential anticancer effects at the cellular and animal level but also are radiosensitizers for some tumors, such as glioblastoma [14] and esophageal squamous cell carcinoma(ESCC) [46]. VPA, a HDACi, increases histone acetylation level, affects chromatin structure and gene regulation by inhibiting HDACs activity $[42,44,47,48]$. Our previous studies have shown that $500 \mu \mathrm{M}$ VPA inhibits the proliferation of a variety of breast cancer cells and induce radiosensitivity, suggesting that VPA may be a promising anti-cancer drug and radiosensitizer $[15,16]$. However, a large dose $(500 \mu \mathrm{M})$ of VPA is needed to render such anti-cancer and radiosensitization activities, other studies 
reported that high dose VPA can induce adverse events, such as liver, kidney toxicity and teratogenicity [17-19], therefore there is clinical interest to locate a suitable alternative.

Some scholars have studied and compared the effect of VPA and its derivatives on the survival of HepG2 hepatoma cells [49]. It was found that VPA derivatives inhibit the growth of tumor cells at $40 \mu \mathrm{M}$. HPTA is a VPA derivative and an effective HDAC inhibitor. Studies have shown that in cerebellar granule cells, HPTA at $5 \mu \mathrm{M}$ was able to significantly increased acetylated histone $\mathrm{H} 3(\mathrm{ac}-\mathrm{H} 3)$ level in a dose-dependent manner [6]. In comparison to VPA which at $100 \mu \mathrm{M}$ increases the level of ac-H3 by $200 \%$, HPTA at 50$100 \mu \mathrm{M}$ increases the level of ac-H3 by $600 \%-700 \%$ [6]. In this study,we demonstrated that HPTA had both anti-cancer and radiosensitizing effects on breast cancer, and that HTPA is more efficacious than VPA since a lower concentration of HPTA is needed to achieve effects as high concentration of VPA. The findings of HPTA's radiosensitizing effect is novel.

A series of our previous studies other group studies have shown that the mechanism of VPA-induced radiosensitization involves the DNA damage repair mechanisms by inducing more DSBs damage to accumulate in the tumor cells, the broken DSBs are unable to be repaired effectively thus lead to the lethality of tumor cells from IR $[15,16]$. Our current findings that HPTA acts in a similar mechanism of action to VPA by disrupting BRCA1-Rad51 mediated HR repair pathway (Figure. 8).

For the NHEJ repair, whilst VPA can inhibit Ku70 and Ku80 proteins in EUFA423 cells similar to our previous report [16], HPTA affects the NHEJ independent of the major repair proteins such as Ku70, Ku80 and DNA PKcs in both MCF7 and EUFA423 cells. The data indicated that there is a different mechanism of action between HPTA and VPA in regulating DNA NHEJ repair function. It may be possible that HPTA influences other NHEJ-related proteins and should be subject to further exploration.

We found that HPTA inhibits the synthesis of BRCA1 and Rad51 protein and shortens their half-life indicating that BRCA1 and Rad51 are the key target proteins in mediating HPTA radiosensitization. HPTA can induce the activation of 53BP1, which forms a barrier that inhibits DNA-end resection [50]. Although BRCA1 can promote DNA-end resection by relieving the 53BP1-dependent barrier [51], HPTA inhibits BRCA1 protein synthesis and promotes degradation, which is undoubtedly bad for HR repair. We therefore hypothesize that HPTA may lead to the failure of forming Rad51 nucleoprotein filaments on damaged single-stranded DNA ends in time, since this process requires the presence of a large number of Rad51 proteins [52], and the homology search and strand exchange mediated by Rad51 nucleoprotein filaments are key steps of the homologous recombination process [53]. The inhibition of Rad51 synthesis and the shortening of its half life cycle are fatal to the HR repair of tumor cells, and should be further investigated.

In summary, our work has bridged laboratory research and clinical practice: HPTA is a more efficacious radiosensitizer than VPA, and its clinical application warrants further investigation and promotion.

\section{Abbreviations}

VPA: valproic acid; HPTA: 2-hexyl-4-pentynoic acid; HR: homologous recombination 
NHEJ: non-homologous end joining; DAB: 3,3'-diaminobenzidine; DMBA: 7,12-dimethylbenz[a]anthracene; DSBs: DNA double strand breaks; FBS: fetal bovine serum; HDACi: histone deacetylase inhibitor; HE:

hematoxylin and eosin; IHC: immunohistochemistry; IR: ionizing radiation; SD: Sprague-Dawley; TBS: TrisBuffered Saline; wtBRCA1: wild type BRCA; ACS2: 2-propyl-pentanoic acid 4-(3H-1,2-dithiole-3-thione-5-yl)phenyl ester; P-V: phospho-valproic acid; ACS33: 2-propyl- pentanoic acid 2-methanesulfonylsulfanylethyl ester; ATCC: American Type Culture Collection; MTT: 3-(4,5-Dimethylthiazol-2-yl)-2,5diphenyltetrazolium bromide; SF: survival fraction; PE: plating efficiency; $\mathrm{CHX}$ : Cycloheximide

\section{Declarations}

\section{Availability of data and materials}

The analyzed datasets generated during the current study are available from the corresponding author on reasonable request.

\section{Ethics approval and consent to participate}

The studies of animal tissue were performed in accordance with the requirements of the Shandong University Human and Animal Ethics Research Committee (81472800,approved March 2014).

\section{Consent for publication}

Not applicable.

\section{Competing interests}

The authors declare that they have no competing interests.

\section{Funding}

This research was supported by grants from National Natural Science Foundation of China (No. 81472800), and Department of Science and Technology of Shandong Provence (2019GSF108083).

\section{Authors' contributions}

Zuchao Cai, David Lim and Zhihui Feng designed the study, analyzed the data, and wrote the manuscript. Zuchao Cai and Guochao Liu performed most of the experiments. Wenwen Ding, Zhendong Wang, Zhujun Tian and Junxuan Peng finished the rest part of the experiments in this study, and they analyzed the data and designed the figures. Chao Dong and Fengmei Zhang provided guidance for this work. All authors provided critical feedback on the manuscript. All authors read and approved the final manuscript. 


\section{Acknowledgments}

Not applicable.

\section{References}

1. Woolston C: Breast cancer. Nature 2015, 527(7578):S101.

2. Ahmad A: Breast Cancer Statistics: Recent Trends. Adv Exp Med Bio/ 2019, 1152:1-7.

3. Kesson EM, Allardice GM, George WD, Burns HJ, Morrison DS: Effects of multidisciplinary team working on breast cancer survival: retrospective, comparative, interventional cohort study of 13722 women. BMJ 2012, 344: e2718.

4. Rutqvist LE, Rose $C$, Cavallin-Stahl E: A systematic overview of radiation therapy effects in breast cancer. Acta Oncol 2003, 42(5-6):532-545.

5. McGale P, Darby SC, Hall P, Adolfsson J, Bengtsson NO, Bennet AM et al: Incidence of heart disease in 35,000 women treated with radiotherapy for breast cancer in Denmark and Sweden. Radiother Oncol 2011, 100(2):167-175.

6. Leng Y, Marinova Z, Reis-Fernandes MA, Nau H, Chuang DM: Potent neuroprotective effects of novel structural derivatives of valproic acid: potential roles of HDAC inhibition and HSP70 induction. Neurosci Lett 2010, 476(3):127-132.

7. Karagiannis TC, $\mathrm{Kn} \mathrm{H}$, El-Osta A: The epigenetic modifier, valproic acid, enhances radiation sensitivity. Epigenetics 2006, 1(3):131-137.

8. Kawano T, Akiyama M, Agawa-Ohta M, Mikami-Terao Y, Iwase S, Yanagisawa T et al: Histone deacetylase inhibitors valproic acid and depsipeptide sensitize retinoblastoma cells to radiotherapy by increasing H2AX phosphorylation and p53 acetylation-phosphorylation. Int J Oncol 2010, 37(4):787-795.

9. Kuendgen A, Gattermann N: Valproic acid for the treatment of myeloid malignancies. Cancer 2007, 110(5):943-954.

10. Duenas-Gonzalez A, Candelaria M, Perez-Plascencia C, Perez-Cardenas E, de la Cruz-Hernandez E, Herrera LA: Valproic acid as epigenetic cancer drug: preclinical, clinical and transcriptional effects on solid tumors. Cancer Treat Rev 2008, 34(3):206-222.

11. Chen X, Wong P, Radany E, Wong JY: HDAC inhibitor, valproic acid, induces p53-dependent radiosensitization of colon cancer cells. Cancer Biother Radiopharm 2009, 24(6):689-699.

12. Entin-Meer M, Rephaeli A, Yang X, Nudelman A, VandenBerg SR, Haas-Kogan DA: Butyric acid prodrugs are histone deacetylase inhibitors that show antineoplastic activity and radiosensitizing capacity in the treatment of malignant gliomas. Mol Cancer Ther 2005, 4(12):1952-1961.

13. Thotala D, Karvas RM, Engelbach JA, Garbow JR, Hallahan AN, DeWees TA et al: Valproic acid enhances the efficacy of radiation therapy by protecting normal hippocampal neurons and sensitizing malignant glioblastoma cells. Oncotarget 2015, 6(33):35004-35022. 
14. Zhang H, Zhang W, Zhou Y, Jiang Y, Li S: Dual Functional Mesoporous Silicon Nanoparticles Enhance the Radiosensitivity of VPA in Glioblastoma. Trans/ Oncol 2017, 10(2):229-240.

15. Liu G, Wang H, Zhang F, Tian Y, Tian Z, Cai Z et al: The Effect of VPA on Increasing Radiosensitivity in Osteosarcoma Cells and Primary-Culture Cells from Chemical Carcinogen-Induced Breast Cancer in Rats. Int $J$ Mol Sci 2017, 18(5).

16. Luo $Y$, Wang $H$, Zhao $X$, Dong $C$, Zhang F, Guo $G$ et al: Valproic acid causes radiosensitivity of breast cancer cells via disrupting the DNA repair pathway. Toxicol Res (Camb) 2016, 5(3):859-870.

17. Perrino E, Cappelletti G, Tazzari V, Giavini E, Del Soldato P, Sparatore A: New sulfurated derivatives of valproic acid with enhanced histone deacetylase inhibitory activity. Bioorg Med Chem Lett 2008, 18(6):1893-1897.

18. Gravemann U, Volland J, Nau H: Hydroxamic acid and fluorinated derivatives of valproic acid: anticonvulsant activity, neurotoxicity and teratogenicity. Neurotoxicol Terato/ 2008, 30(5):390-394.

19. Wedel SA, Sparatore A, Soldato PD, Al-Batran SE, Atmaca A, Juengel E et al: New histone deacetylase inhibitors as potential therapeutic tools for advanced prostate carcinoma. J Cell Mol Med 2008, 12(6a):2457-2466.

20. Mackenzie GG, Huang L, Alston N, Ouyang N, Vrankova K, Mattheolabakis G et al: Targeting mitochondrial STAT3 with the novel phospho-valproic acid (MDC-1112) inhibits pancreatic cancer growth in mice. PLoS One 2013, 8(5):e61532.

21. Tesei A, Brigliadori G, Carloni S, Fabbri F, Ulivi P, Arienti C et al: Organosulfur derivatives of the HDAC inhibitor valproic acid sensitize human lung cancer cell lines to apoptosis and to cisplatin cytotoxicity. J Cell Physiol 2012, 227(10):3389-3396.

22. Eikel D, Lampen A, Nau H: Teratogenic effects mediated by inhibition of histone deacetylases: evidence from quantitative structure activity relationships of $\mathbf{2 0}$ valproic acid derivatives. Chem Res Toxicol 2006, 19(2):272-278.

23. Lampen A, Siehler S, Ellerbeck U, Gottlicher M, Nau H: New molecular bioassays for the estimation of the teratogenic potency of valproic acid derivatives in vitro: activation of the peroxisomal proliferatoractivated receptor (PPARdelta). Toxicol Appl Pharmacol 1999, 160(3):238-249.

24. Feng Z, Scott SP, Bussen W, Sharma GG, Guo G, Pandita TK et al: Rad52 inactivation is synthetically lethal with BRCA2 deficiency. Proc Natl Acad Sci U S A 2011, 108(2):686-691.

25. Gunn A, Stark JM: I-Scel-based assays to examine distinct repair outcomes of mammalian chromosomal double strand breaks. Methods Mol Biol 2012, 920:379-391.

26. He G, Wang Y, Pang X, Zhang B: Inhibition of autophagy induced by TSA sensitizes colon cancer cell to radiation. Tumour Biol 2014, 35(2):1003-1011.

27. Wang F, Ma Z, Wang F, Fu Q, Fang Y, Zhang Q et al: Establishment of novel rat models for premalignant breast disease. Chin Med J (Engl) 2014, 127(11):2147-2152.

28. Tian Y, Liu G, Wang H, Tian Z, Cai Z, Zhang F et al: Valproic acid sensitizes breast cancer cells to hydroxyurea through inhibiting RPA2 hyperphosphorylation-mediated DNA repair pathway. DNA Repair (Amst) 2017, 58:1-12. 
29. Harbeck N, Gnant M: Breast cancer. Lancet 2017, 389(10074):1134-1150.

30. Polo SE, Blackford AN, Chapman JR, Baskcomb L, Gravel S, Rusch A et al: Regulation of DNA-end resection by hnRNPU-like proteins promotes DNA double-strand break signaling and repair. $\mathrm{Mol} \mathrm{Cell}$ 2012, 45(4):505-516.

31. Schwertman P, Bekker-Jensen S, Mailand N: Regulation of DNA double-strand break repair by ubiquitin and ubiquitin-like modifiers. Nat Rev Mol Cell Biol 2016, 17(6):379-394.

32. Ha GH, Ji JH, Chae S, Park J, Kim S, Lee JK et al: Pellino1 regulates reversible ATM activation via NBS1 ubiquitination at DNA double-strand breaks. Nat Commun 2019, 10(1):1577.

33. Vaclova T, Gomez-Lopez G, Setien F, Bueno JM, Macias JA, Barroso A et al: DNA repair capacity is impaired in healthy BRCA1 heterozygous mutation carriers. Breast Cancer Res Treat 2015, 152(2):271-282.

34. Wu L, Shao L, Li M, Zheng J, Wang J, Feng W et al: BMS-345541 sensitizes MCF-7 breast cancer cells to ionizing radiation by selective inhibition of homologous recombinational repair of DNA doublestrand breaks. Radiat Res 2013, 179(2):160-170.

35. Zhou Y, Niu J, Li S, Hou H, Xu Y, Zhang W et al: Radioprotective effects of valproic acid, a histone deacetylase inhibitor, in the rat brain. Biomed Rep 2015, 3(1):63-69.

36. Krug D, Baumann R, Budach W, Dunst J, Feyer P, Fietkau R et al: Current controversies in radiotherapy for breast cancer. Radiat Oncol 2017, 12(1):25.

37. Budke B, Logan HL, Kalin JH, Zelivianskaia AS, Cameron McGuire W, Miller LL et al: RI-1: a chemical inhibitor of RAD51 that disrupts homologous recombination in human cells. Nucleic Acids Res 2012, 40(15):7347-7357.

38. Schneider-Poetsch T, Ju J, Eyler DE, Dang Y, Bhat S, Merrick WC et al: Inhibition of eukaryotic translation elongation by cycloheximide and lactimidomycin. Nat Chem Bio/ 2010, 6(3):209-217.

39. Gold PE, Wrenn SM: Cycloheximide impairs and enhances memory depending on dose and footshock intensity. Behav Brain Res 2012, 233(2):293-297.

40. Park WS, Sung DK, Kang S, Koo SH, Kim YJ, Lee JH et al: Therapeutic window for cycloheximide treatment after hypoxic-ischemic brain injury in neonatal rats. J Korean Med Sci 2006, 21(3):490-494.

41. Shi P, Liu W, Tala, Wang H, Li F, Zhang H et al: Metformin suppresses triple-negative breast cancer stem cells by targeting KLF5 for degradation. Cell Discov 2017, 3:17010.

42. Marks PA, Xu WS: Histone deacetylase inhibitors: Potential in cancer therapy. J Cell Biochem 2009, 107(4):600-608.

43. Giannini G, Cabri W, Fattorusso C, Rodriquez M: Histone deacetylase inhibitors in the treatment of cancer: overview and perspectives. Future Med Chem 2012, 4(11):1439-1460.

44. Marks PA: Histone deacetylase inhibitors: a chemical genetics approach to understanding cellular functions. Biochim Biophys Acta 2010, 1799(10-12):717-725.

45. Dokmanovic M, Clarke C, Marks PA: Histone deacetylase inhibitors: overview and perspectives. $\mathrm{Mol}$ Cancer Res 2007, 5(10):981-989. 
46. Makita N, Ninomiya I, Tsukada T, Okamoto K, Harada S, Nakanuma S et al: Inhibitory effects of valproic acid in DNA double-strand break repair after irradiation in esophageal squamous carcinoma cells. Oncol Rep 2015, 34(3):1185-1192.

47. Blattmann C, Oertel S, Ehemann V, Thiemann M, Huber PE, Bischof M et al: Enhancement of radiation response in osteosarcoma and rhabdomyosarcoma cell lines by histone deacetylase inhibition. Int $J$ Radiat Oncol Biol Phys 2010, 78(1):237-245.

48. Zhang H, Dai X, Qi Y, He Y, Du W, Pang JJ: Histone Deacetylases Inhibitors in the Treatment of Retinal Degenerative Diseases: Overview and Perspectives. J Ophthalmo/ 2015, 2015:250812.

49. El-Faham A, Farooq M, Khattab SN, Elkayal AM, Ibrahim MF, Abutaha N et al: Synthesis and biological activity of Schiff base series of valproyl, $\mathrm{N}$-valproyl glycinyl, and $\mathrm{N}$-valproyl-4aminobenzoyl hydrazide derivatives. Chem Pharm Bull (Tokyo) 2014, 62(6):591-599.

50. Shibata A: Regulation of repair pathway choice at two-ended DNA double-strand breaks. Mutat Res 2017, 803-805:51-55.

51. Isono M, Niimi A, Oike T, Hagiwara Y, Sato H, Sekine R et al: BRCA1 Directs the Repair Pathway to Homologous Recombination by Promoting 53BP1 Dephosphorylation. Cell Rep 2017, 18(2):520-532.

52. Carver A, Zhang X: Rad51 filament dynamics and its antagonistic modulators. Semin Cell Dev Biol 2020.

53. Qiu Y, Antony E, Doganay S, Koh HR, Lohman TM, Myong S: Srs2 prevents Rad51 filament formation by repetitive motion on DNA. Nat Commun 2013, 4:2281.

\section{Figures}


Figure 1.

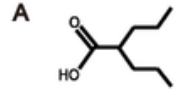

Valproic Acid (VPA) 2-hexyl-4-Pentynoic Acid (HPTA)

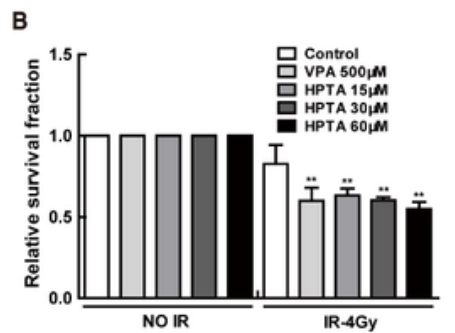

E
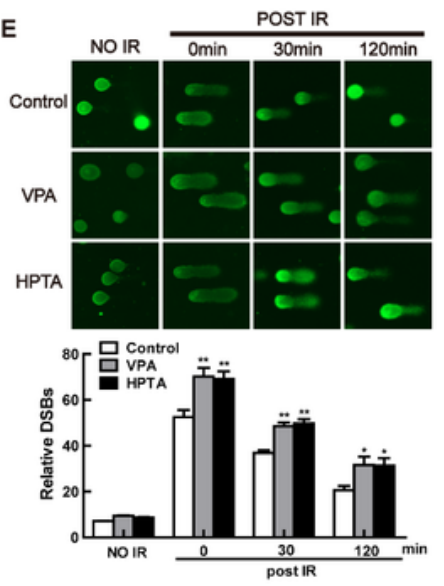
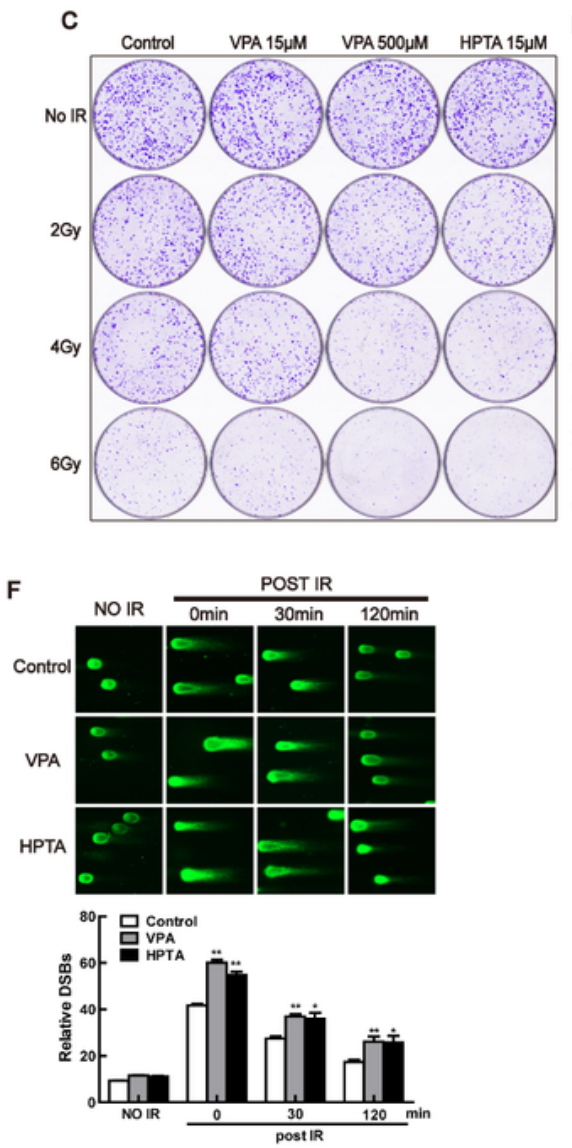

G
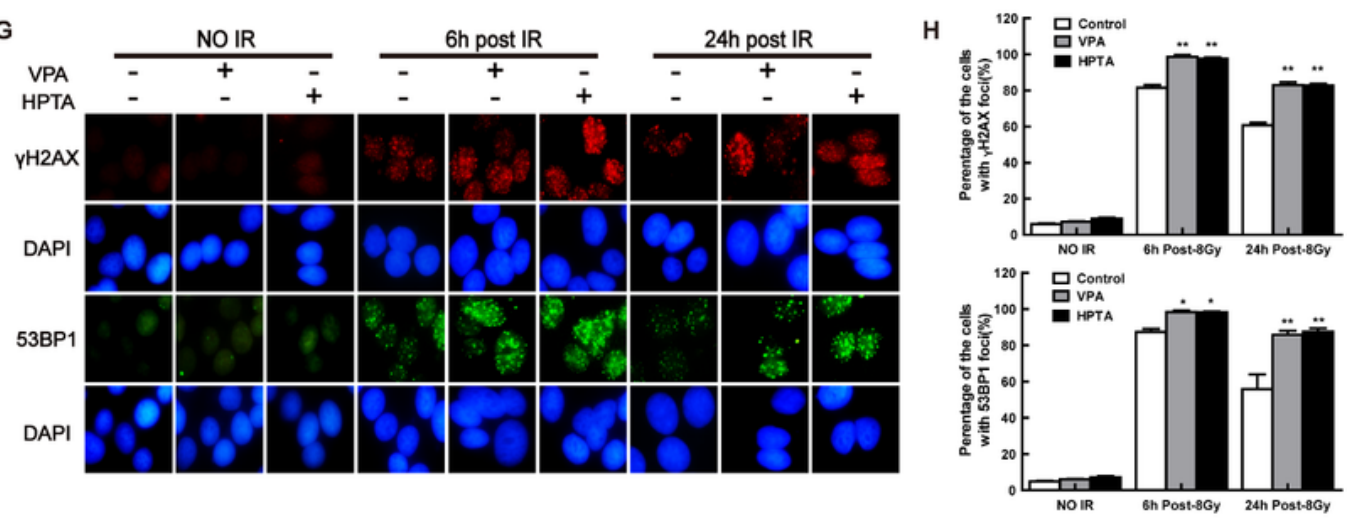

I
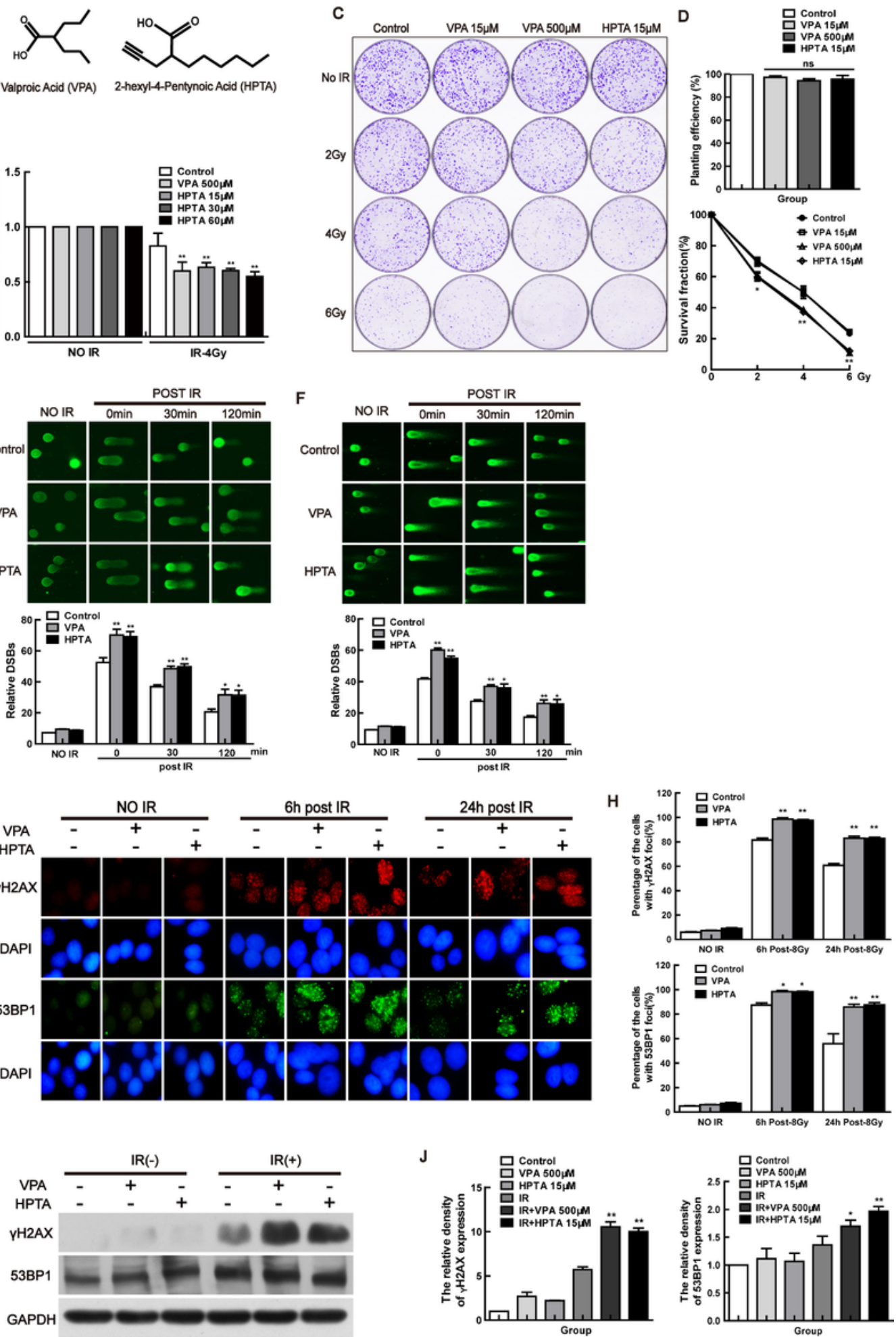

Figure 1

HPTA results in the accumulation of more DSBs in response to IR. (A) The structural formula of VPA (left) and HPTA (right). (B) The cell growth was tested by the MTT assay in MCF7 cells in VPA and HPTA alone or the combination treatment of VPA and HPTA with 4 Gy of IR. (C) Representative results of clonogenic survival in MCF7 cells treated with VPA and HPTA alone or the combination treatment of VPA and HPTA with different doses of $0,2,4$ or 6Gy (upper and down). Cells were treated with VPA or HPTA for $24 \mathrm{~h}$ 
before IR treatment. (D) The planting efficiency (upper) and surviving fraction (down) of the clonogenic survival assay in MCF7 cells. (E) The alkaline comet assay was used for the analysis of DNA DSBs in MCF7 cells (upper) and the relative DSBs were analyzed after normalizing (down). (F) The neutral comet assay was used for the analysis of DNA DSBs in MCF7 cells (upper) and the relative DSBs were analyzed normalizing (down). (G) The dynamic change of IR-induced YH2AX and 53BP1 foci formation in MCF7

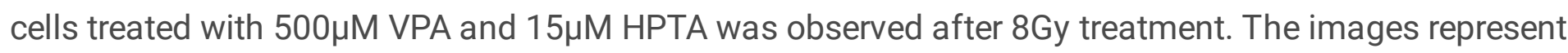
$\mathrm{YH} 2 \mathrm{AX}$ and 53BP1 foci formation in the VPA/HPTA-treated cells at pre-8Gy, $6 \mathrm{~h}$ and $24 \mathrm{~h}$ post-8Gy, DAPI was used for nuclear staining. $(H)$ The percentage of $\mathrm{YH} 2 \mathrm{AX}$ (upper) and 53BP1 (down) foci formation was evaluated. (I) The level of $\mathrm{YH} 2 \mathrm{AX}$ and 53BP1 in MCF7 cells was detected by immunoblotting. $(\mathrm{J})$ The density was further analyzed by the Image $J$ in MCF7 cells. Each data point in the graphs was from three independent experiments (mean $\pm S D$ ). P-values were calculated by Student's t-test $(* P<0.05, * \star P<0.01)$. Figure 2.

A

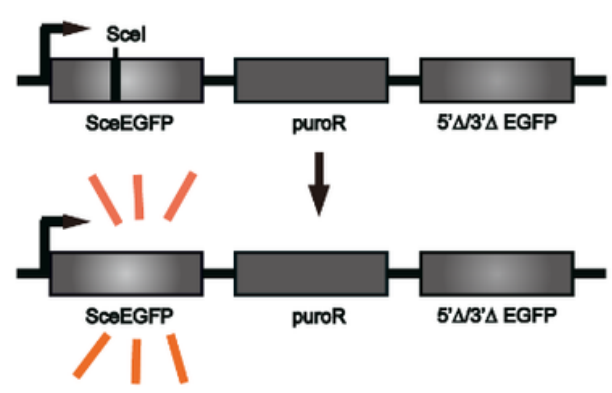

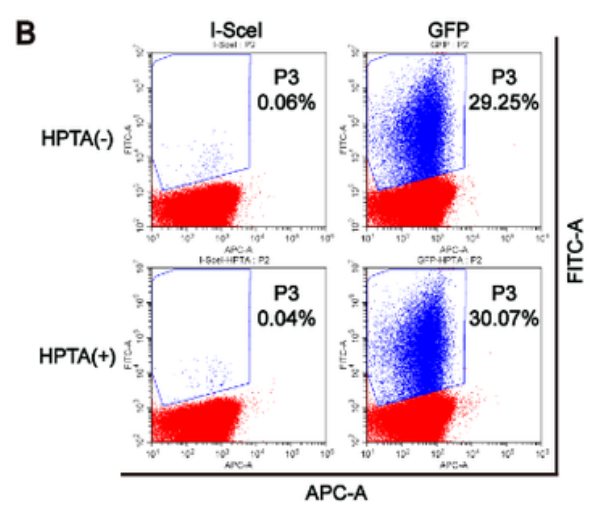

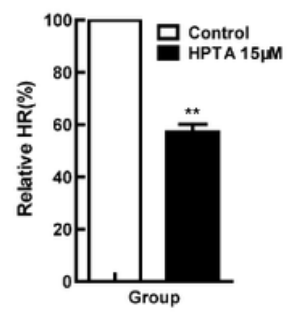

C

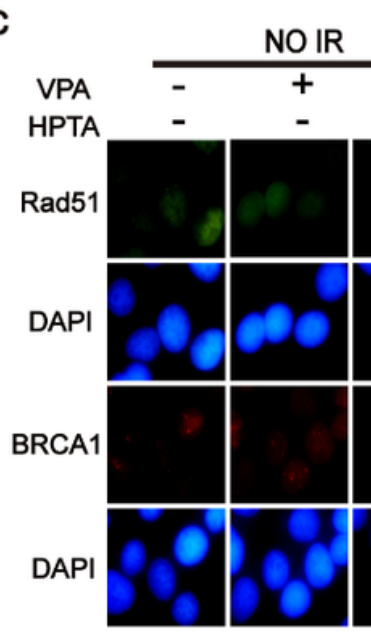

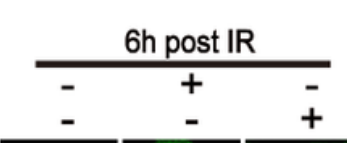
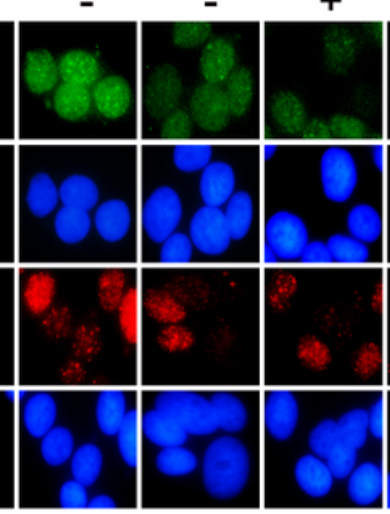

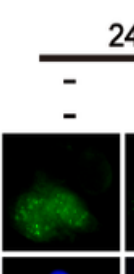

$24 \mathrm{~h}$ post IR
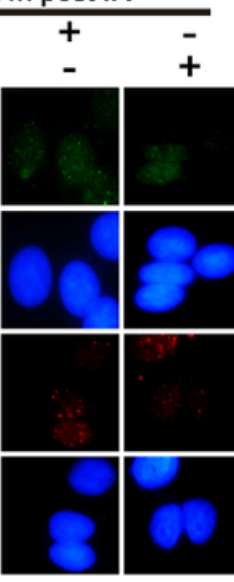

D

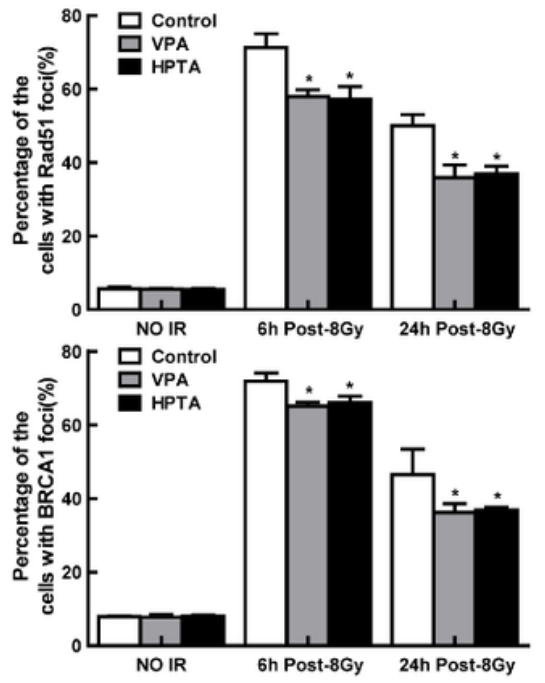

E
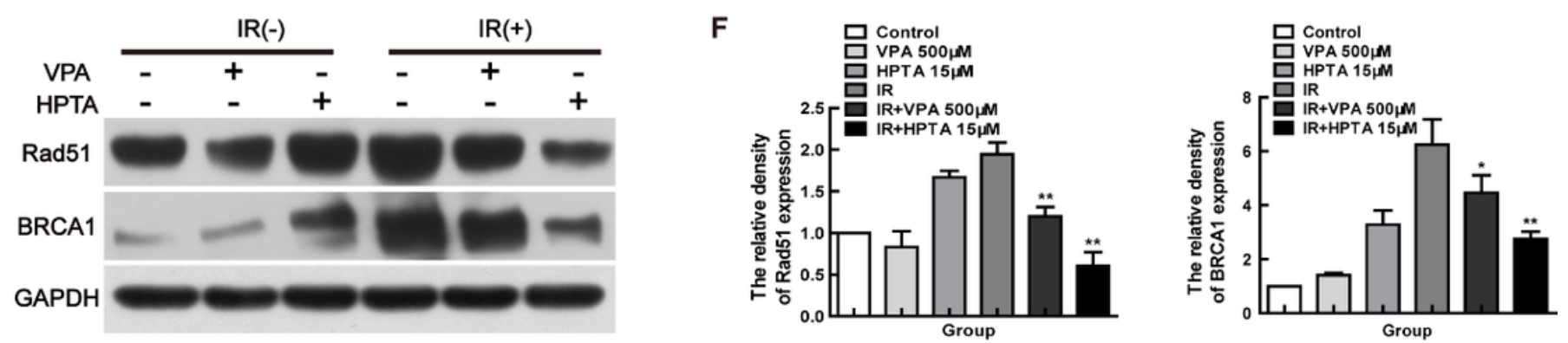

Figure 2 
Low dose HPTA dysregulates DNA repair pathway in response to IR-induced DSBs (A) The working schematic of the recombination substrate, pDR-GFP, was presented. (B) MCF7 cells with pDR-GFP expression were transfected with plasmid of I-Scel or GFP and then treated with $15 \mu \mathrm{M} \mathrm{HPTA}$ for $24 \mathrm{~h}$. GFP was used as a positive control to represent transfection efficiency. The images showed that the results of HR frequency in HPTA treated cells were measured by flow cytometry. (C) The dynamic change

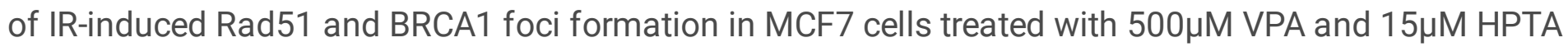
was observed after $8 \mathrm{~Gy}$ treatment. The images represent Rad51 and BRCA1 foci formation in the VPA/HPTA-treated cells at pre-8Gy, $6 \mathrm{~h}$ and $24 \mathrm{~h}$ post-8Gy, DAPI was used for nuclear staining. (D) The percentage of Rad51 (upper) and BRCA1 (down) foci formation was evaluated. (E) The level of Rad51 and BRCA1 in MCF7 cells was detected by immunoblotting. (F) The density was further analyzed by the Image $\mathrm{J}$ in MCF7 cells. Each data point in the graph was from three independent experiments (mean $\square$ SD); P-Values were calculated by t-test $\left({ }^{*} \mathrm{P}<0.05,{ }^{* *} \mathrm{P}<0.01\right)$. 
Figure 3.
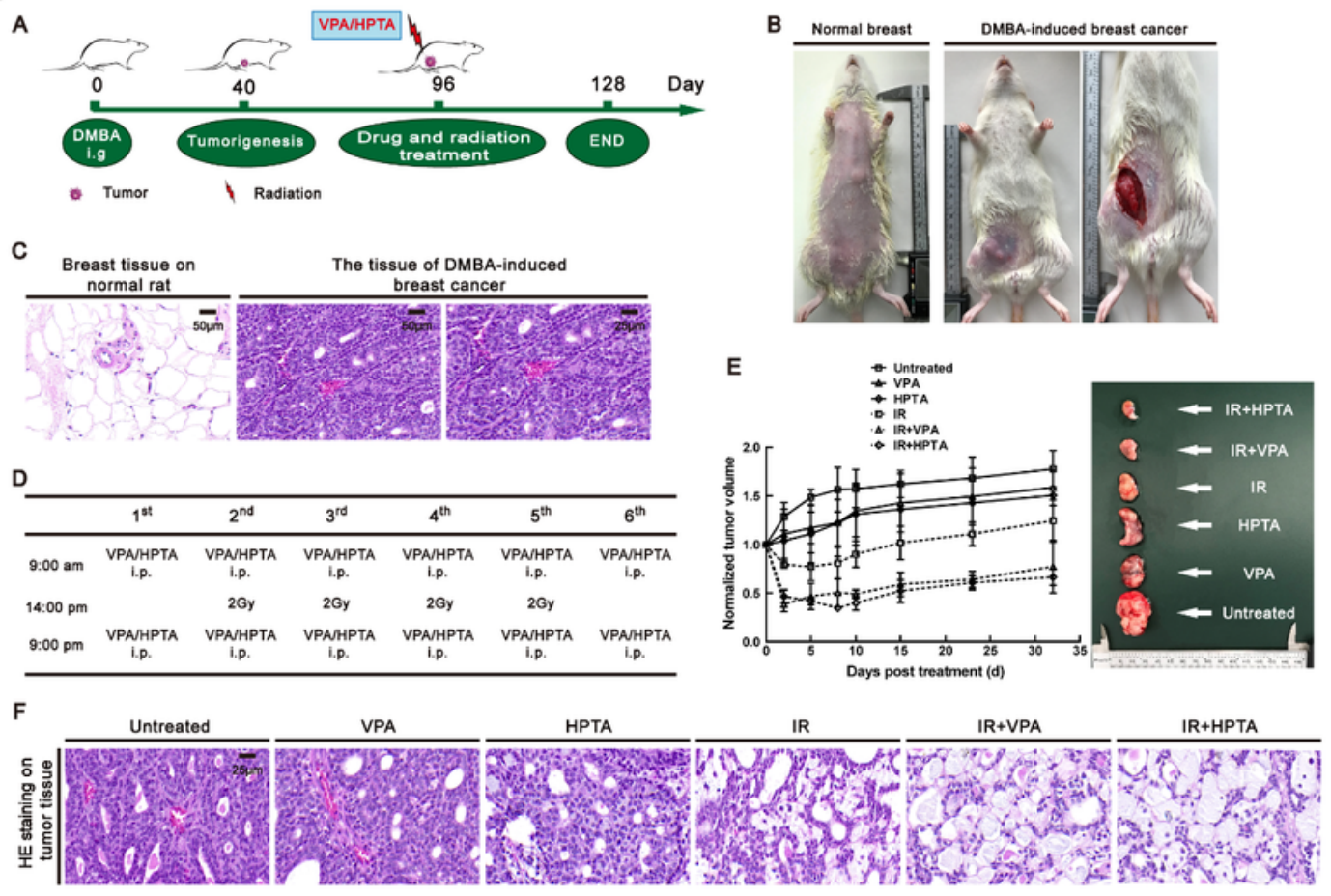

G

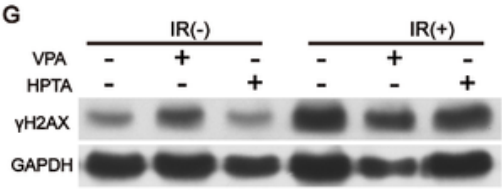

।
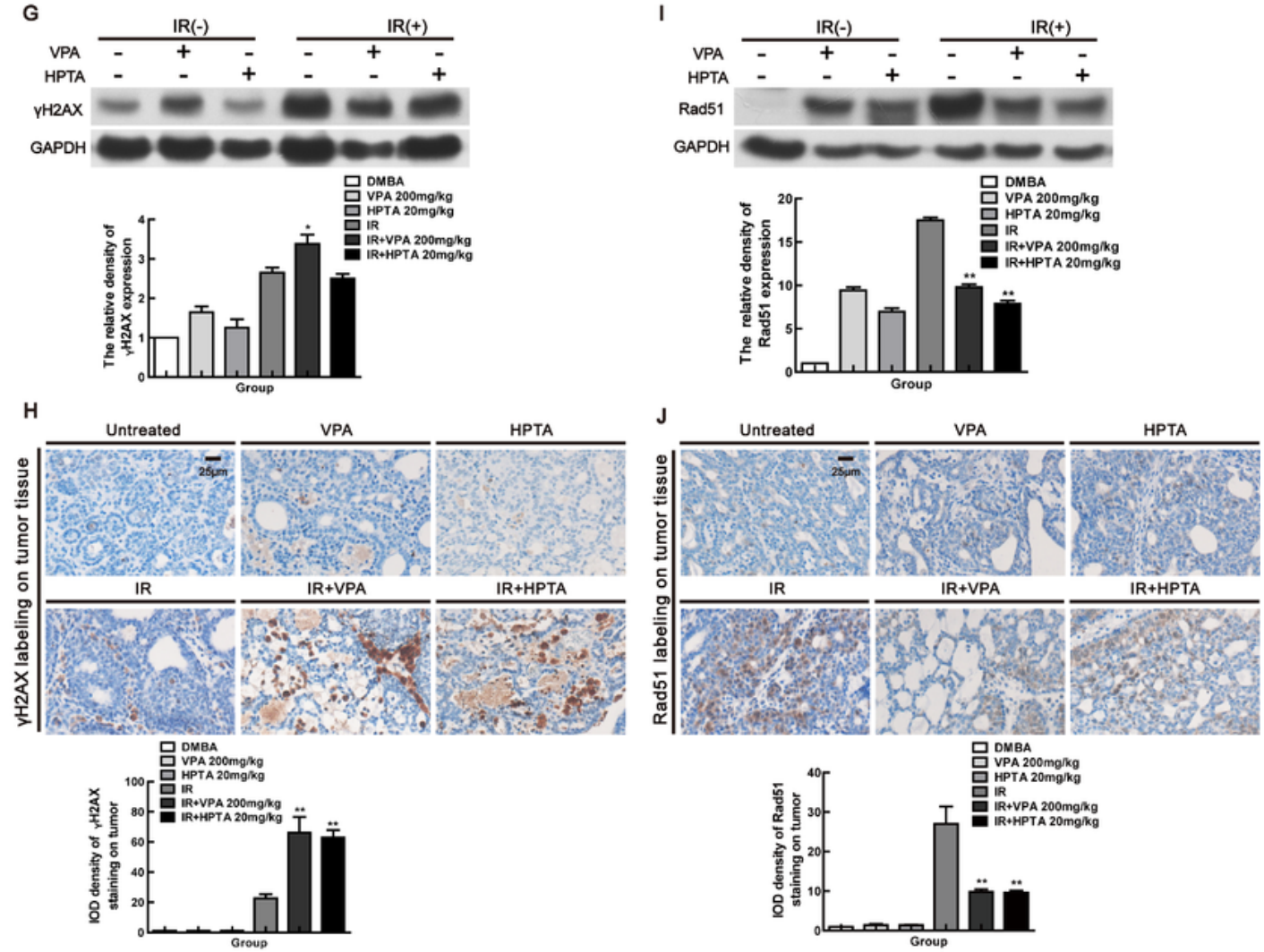

Figure 3

HPTA exhibits radiosensitizing properties to IR treatment in DMBA-induced breast cancer in rats in vivo (A) The scheme of experiment in vivo. (B) Normal breast and DMBA-induced breast cancer of rats under gross observation. (C) HE staining for the morphology of normal tissue and DMBA-induced breast cancer. (D) The schedule of VPA or HPTA administration and 2Gy $\times$ 4days IR treatment. 200mg/kg VPA or $20 \mathrm{mg} / \mathrm{kg}$ HPTA injected (i.p.) into rats every $12 \mathrm{hrs}$. VPA or HPTA injection was performed before and after 
the daily 2Gy irradiation, totaling 12 times of VPA or HPTA injection. (E) The change of tumor volumes in different groups after treatment, which was normalized by the untreated group. (F) The morphological change of tumor in groups after treatment was outlined in the scheme as was shown by HE staining. (G) The protein level of $\square \mathrm{H} 2 \mathrm{AX}$ was detected by western blot using the whole lysate of treated tumor tissues. Bands were quantified by Image $\mathrm{J}$ software. $(\mathrm{H}) \mathrm{\square H} 2 \mathrm{AX}$ expression in situ was detected by immunohistochemical staining and the IOD density was analyzed. (I) The protein level of Rad51 was detected by western blot using the whole lysate of treated tumor tissues. Bands were quantified by Image $\mathrm{J}$ software. (J) Rad51 expression in situ was detected by immunohistochemical staining and the IOD density was analyzed. Each data point in the graph was from three independent experiments (mean $\square$ $\mathrm{SD})$; P-Values were calculated by t-test $\left({ }^{*} \mathrm{P}<0.05,{ }^{*} \mathrm{P}<0.01\right)$. 
Figure 4.

A

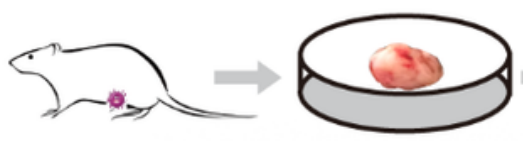

PBS

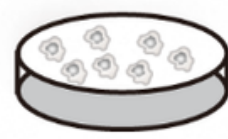

DMEM, $10 \%$ FBS

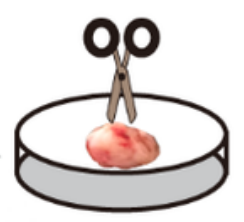

DMEM

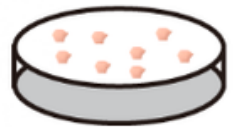

DMEM, 10\%FBS

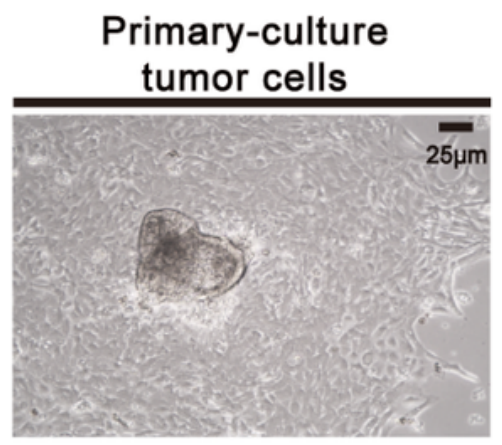

B
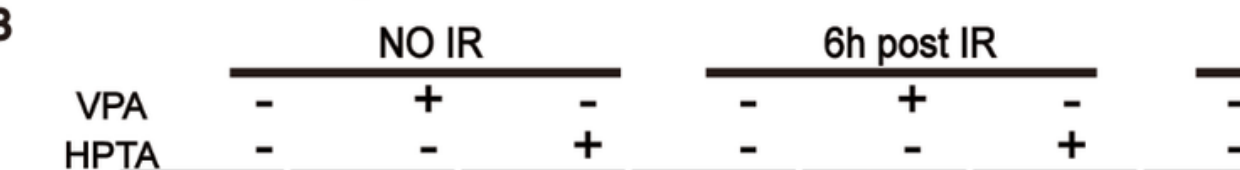

24h post IR
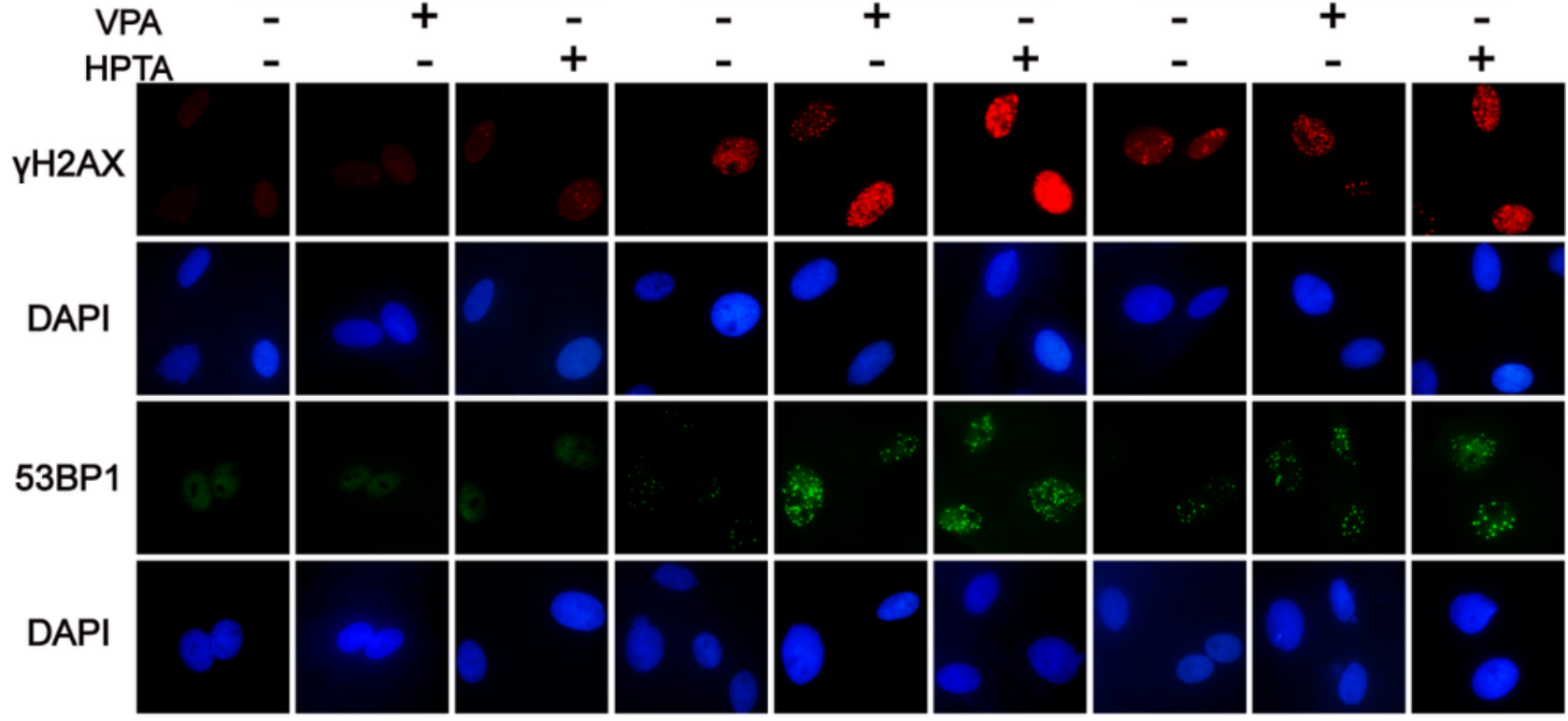

C
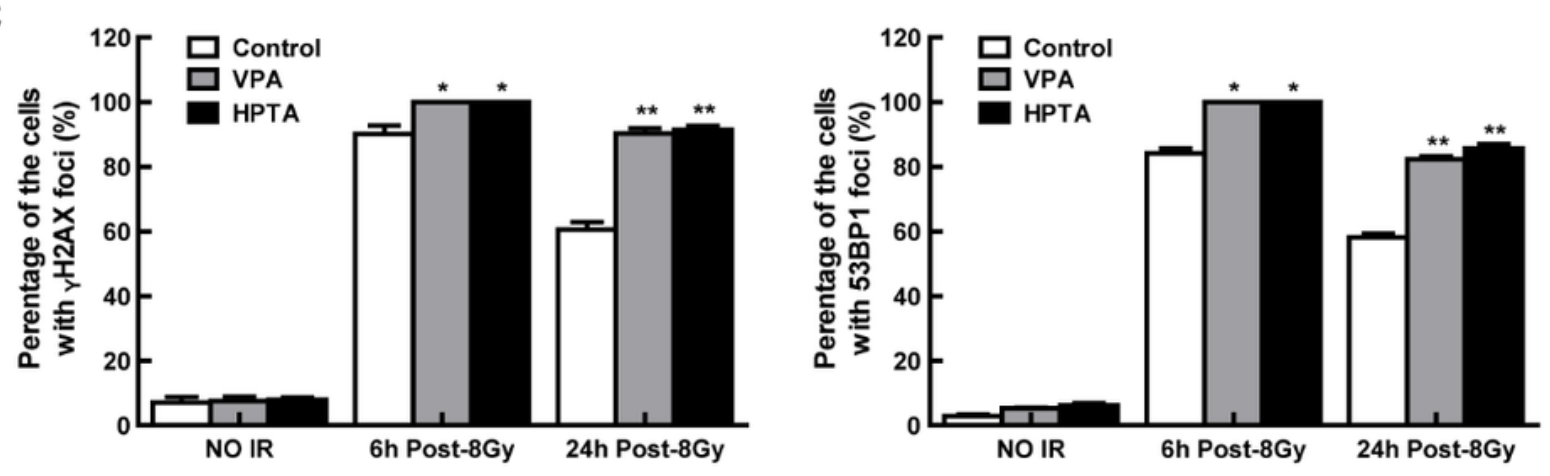

Figure 4

The role of HPTA on the radiosensitivity of DMBA-induced rat breast cancer-derived primary cells (A) The culture of DMBA-induced rat breast cancer-derived primary cells. (B) The dynamic change of IR-induced

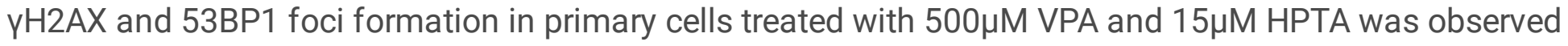
after 8Gy treatment. The images represent $\mathrm{YH} 2 \mathrm{AX}$ and 53BP1 foci formation in the VPA/HPTA-treated cells at pre-8Gy, $6 \mathrm{~h}$ and $24 \mathrm{~h}$ post-8Gy, DAPI was used for nuclear staining. (C) The percentage of $\mathrm{yH} 2 \mathrm{AX}$ 
(upper) and 53BP1 (down) foci formation was evaluated. Each data point in the graph was from three independent experiments (mean $\triangle \mathrm{SD})$; P-Values were calculated by t-test $\left({ }^{*} \mathrm{P}<0.05,{ }^{*} \mathrm{P}<0.01\right)$.

Figure 5.
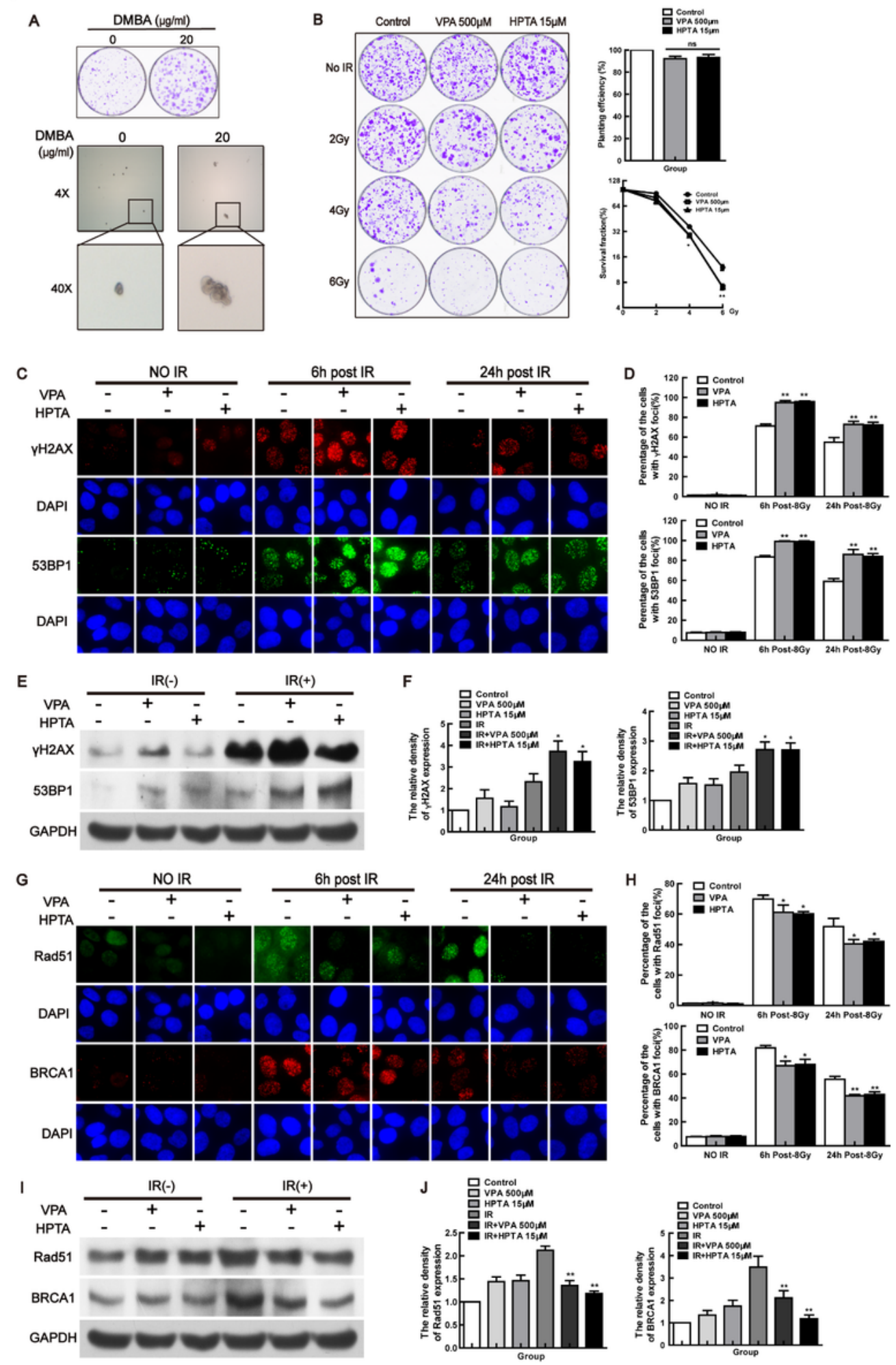

\section{Figure 5}

The role of HPTA on the radiosensitivity of DMBA-induced transformed human normal breast cell line (A) Clonogenic survival assay and soft agar assay showed the forming colonies after 4 weeks of culturing to identify cell transforming. (B) Representative results of clonogenic survival in DMBA-induced transformed 
human normal breast cells treated with VPA and HPTA alone or the combination treatment of VPA and HPTA with different doses of 0, 2, 4, or 6Gy. (C) The dynamic change of IR-induced YH2AX and 53BP1

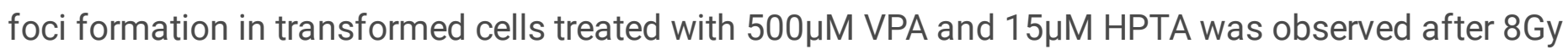
treatment. The images represent $\mathrm{YH} 2 \mathrm{AX}$ and 53BP1 foci formation in the VPA/HPTA-treated cells at pre$8 \mathrm{~Gy}, 6 \mathrm{~h}$ and $24 \mathrm{~h}$ post-8Gy, DAPI was used for nuclear staining. (D) The percentage of $\mathrm{YH} 2 \mathrm{AX}$ (upper) and 53BP1 (down) foci formation was evaluated. (E) The level of YH2AX and 53BP1 in transformed cells was detected by immunoblotting. (F) The density was further analyzed by the Image $J$ in transformed cells. (G) The dynamic change of IR-induced Rad51 and BRCA1 foci formation in transformed cells treated with $500 \mu \mathrm{M}$ VPA and $15 \mu \mathrm{M}$ HPTA was observed after $8 \mathrm{~Gy}$ treatment. The images represent Rad51 and BRCA1 foci formation in the VPA/HPTA-treated cells at pre-8Gy, $6 \mathrm{~h}$ and $24 \mathrm{~h}$ post-8Gy, DAPI was used for nuclear staining. $(\mathrm{H})$ The percentage of Rad51 (upper) and BRCA1 (down) foci formation was evaluated. (I) The level of Rad51 and BRCA1 in transformed cells was detected by immunoblotting. ( $\mathrm{J}$ ) The density was further analyzed by the Image $J$ in transformed cells. Each data point in the graph was from three independent experiments (mean $\otimes S D) ; P$-Values were calculated by t-test $\left({ }^{\star} P<0.05, * \star P<0.01\right)$. 
Figure 6.

A

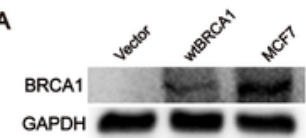

C
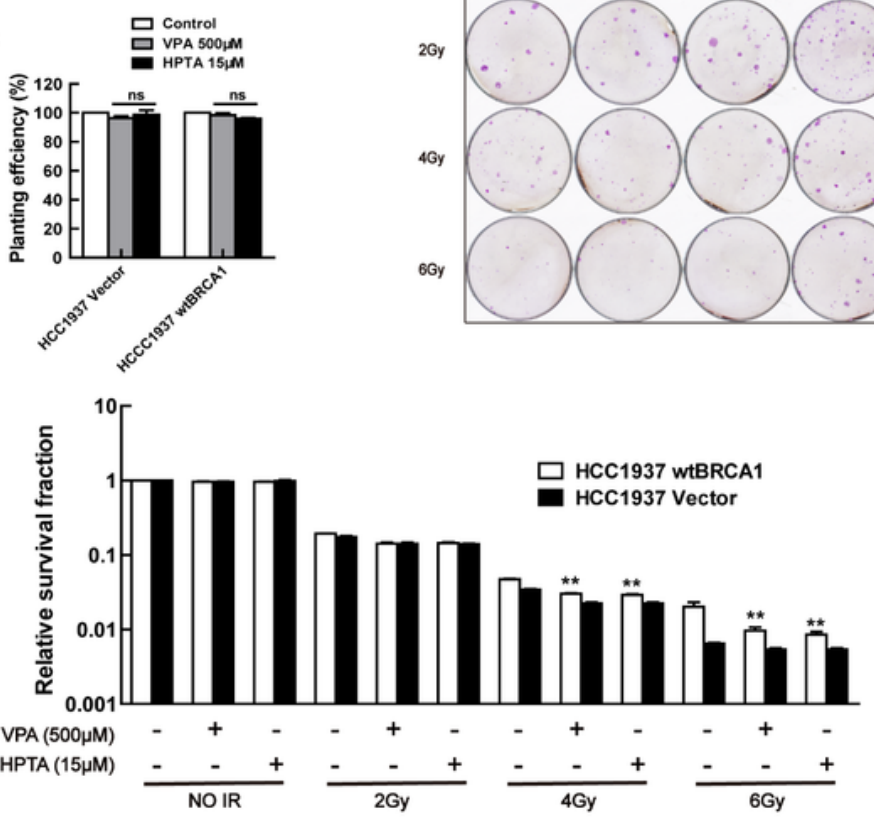

D

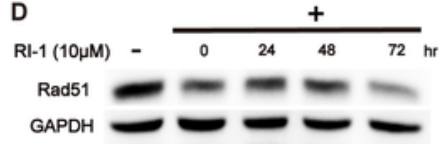

F
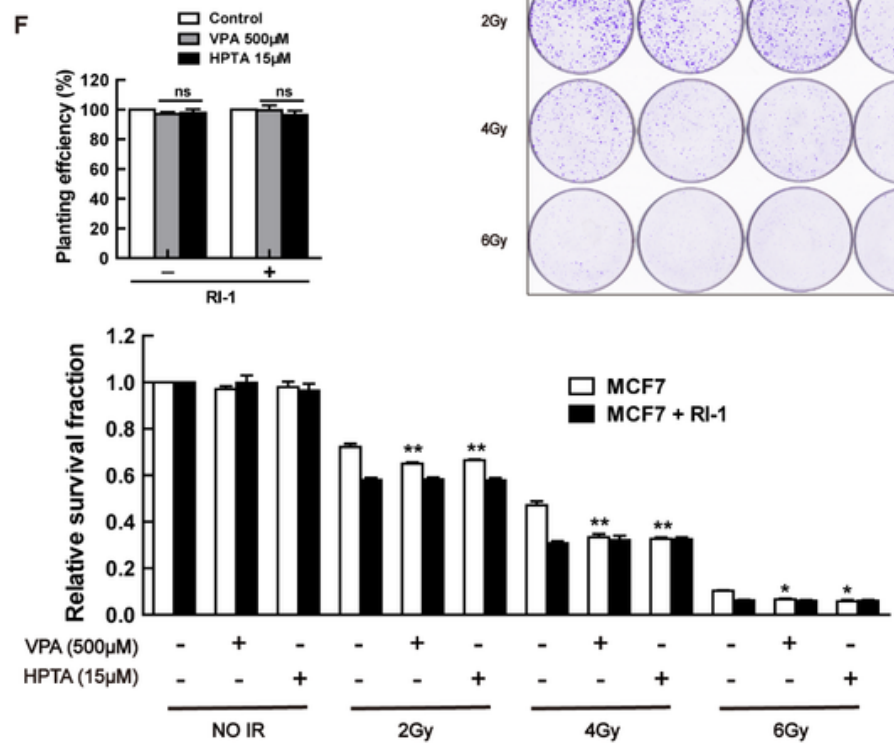

Figure 6

HPTA-mediated radiosensitization of breast cancer cells is dependent on BRCA1 and Rad51 proteins (A) $\mathrm{RI}-1$, an inhibitor of Rad51, was used to down-regulate the expression of Rad51 in MCF7 cells. (B) By colony formation assay, cell survival in the paired cell lines was performed after different treatments. (C) Survival fractions in deferent groups were showed. (D) The stable expressed cell line of BRCA1-deficient and BRCA1-proficient was successfully established by BRCA1-deficient cell line, HCC1937. (E) By colony
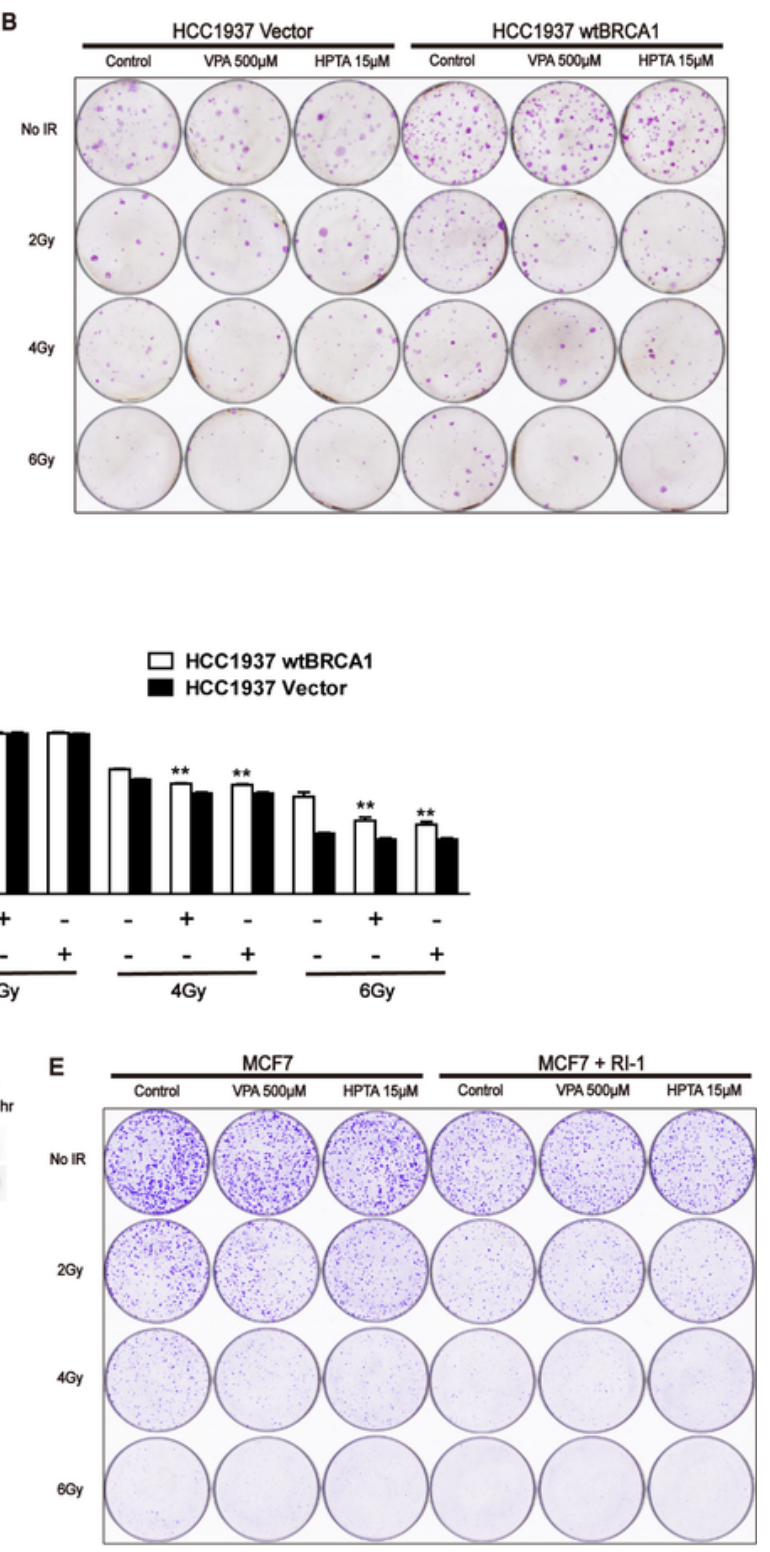
formation assay, cell survival in the paired cell lines was performed after different treatments. (F) Survival fractions in deferent groups were showed. Each data point in the graphs was from three independent experiments (mean $\otimes S D)$; P-Values were calculated by t-test $\left({ }^{*} P<0.05, * * P<0.01\right)$.

\section{Figure 7.}

A

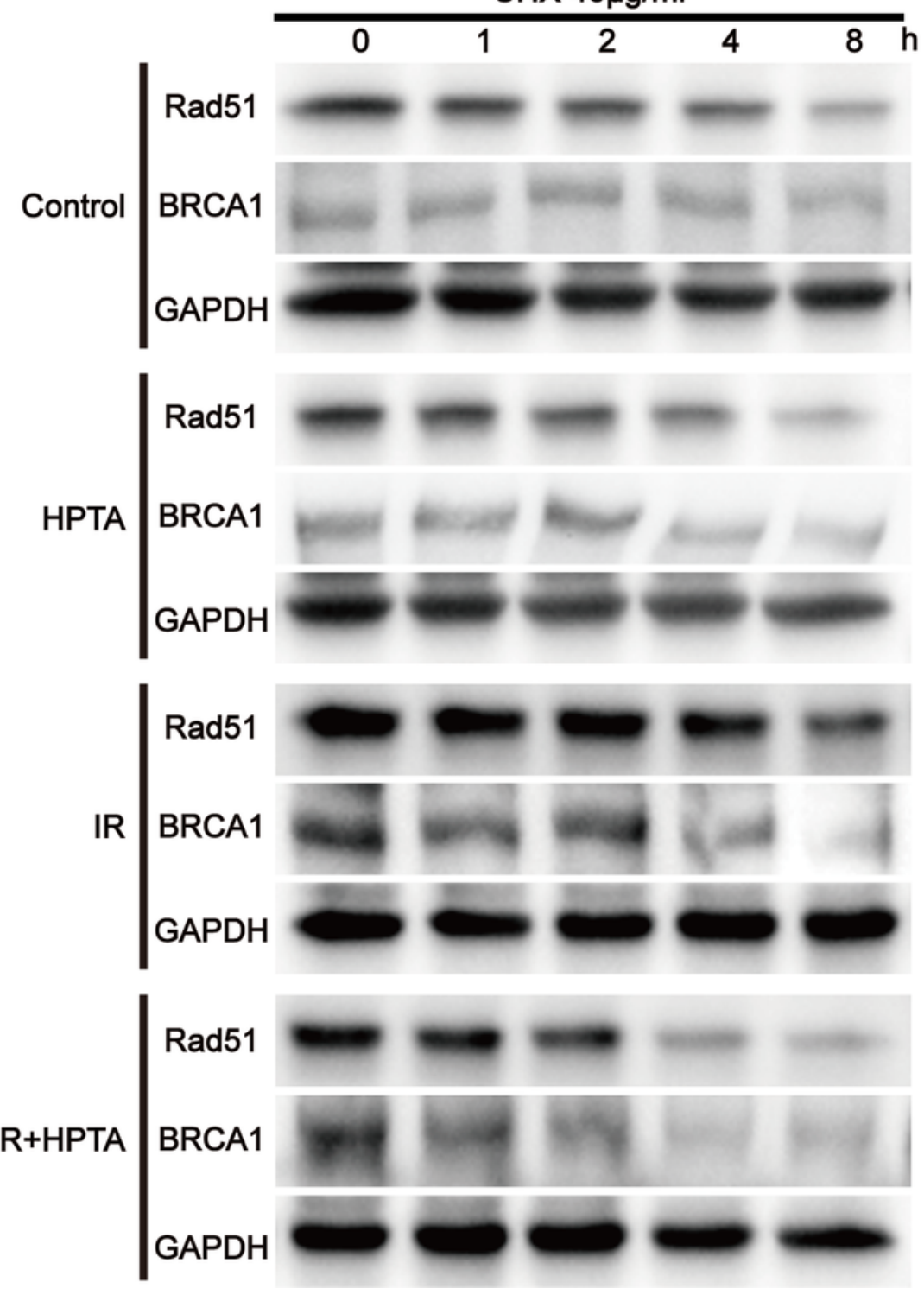

B

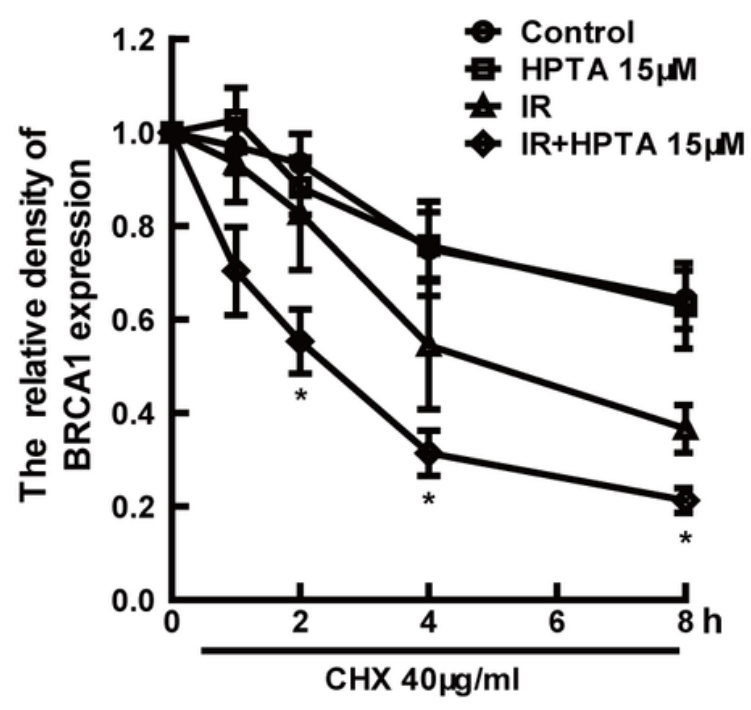

C

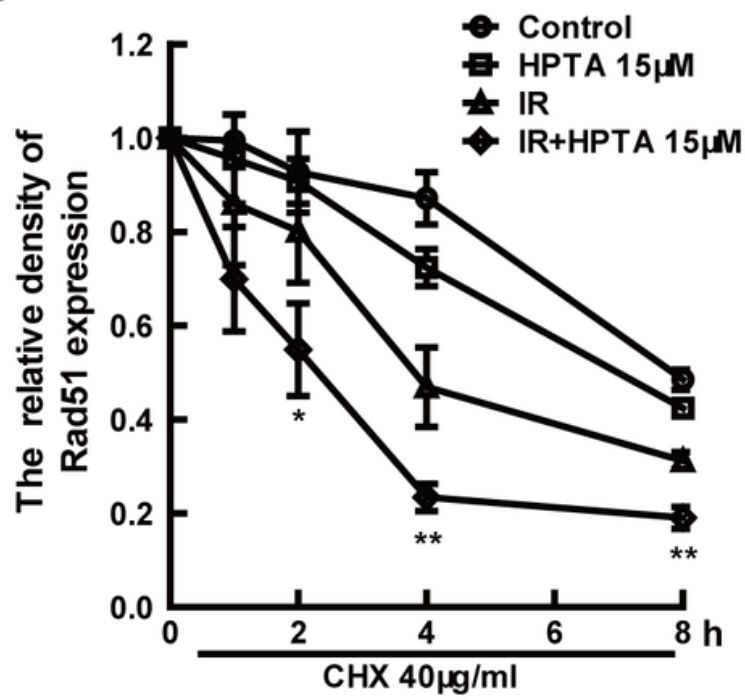

Figure 7

HPTA increases the sensitivity of breast tumor cells to radiotherapy by inhibiting BRCA1 and Rad51 protein synthesis and shortening their half-life (A) After 0, 1, 2, 4, 8 hours treatment with Cycloheximide (CHX), the protein changes of Rad51 and BRCA1 were detected by immunoblotting. (B) Analysis of results in $A$ (after correction). Each data point in the graphs was from three independent experiments (mean $\otimes S D) ; P$-Values were calculated by t-test $\left({ }^{*} P<0.05\right.$, ** $\left.P<0.01\right)$. 
Figure 8.

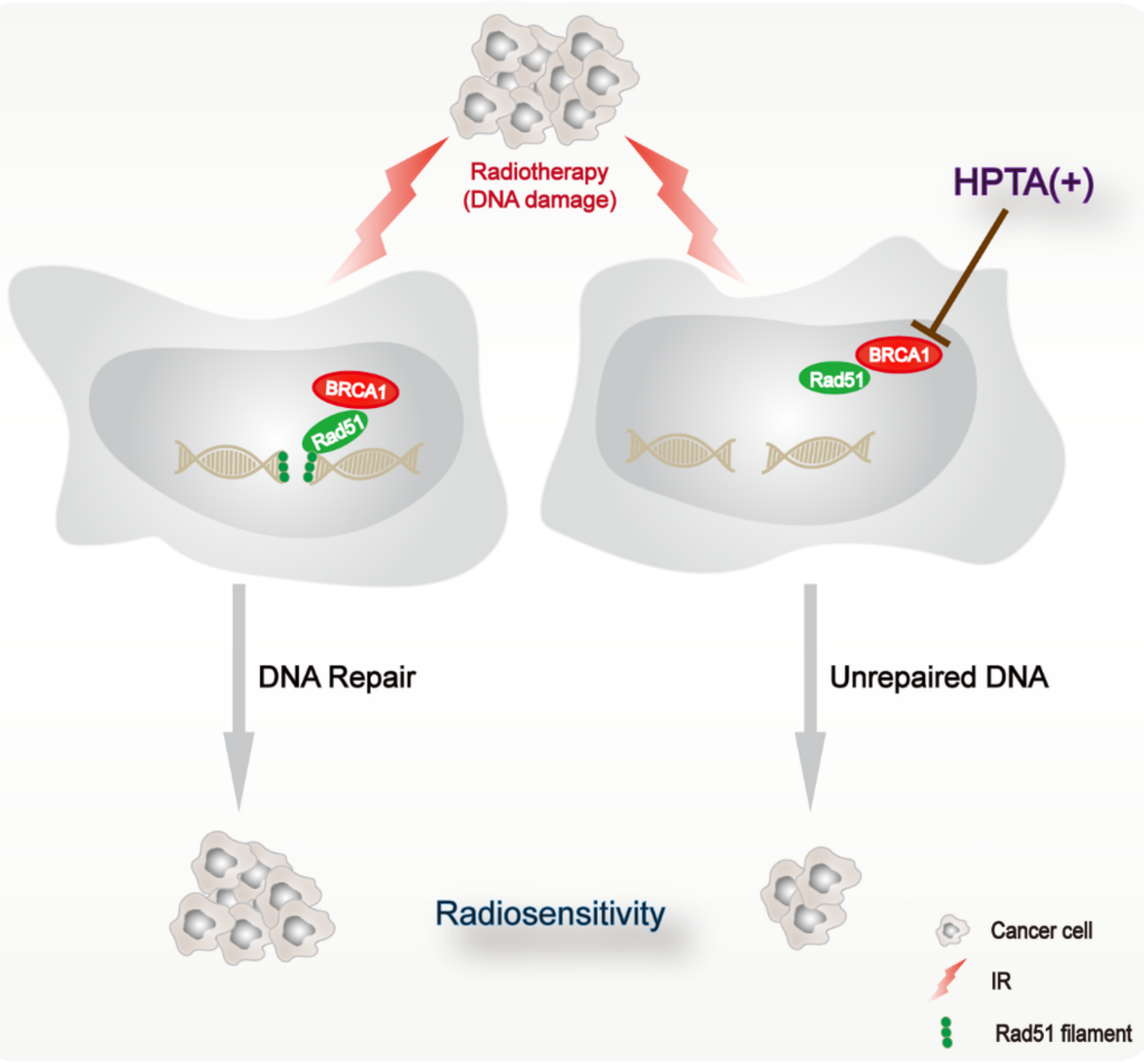

Figure 8

The molecular model of the combination of HPTA and IR to suppress breast cancer cells through BRCA1Rad51 mediated HR repair pathway.

\section{Supplementary Files}

This is a list of supplementary files associated with this preprint. Click to download.

- Supplementaryfigures.docx 